\title{
I_Pinnacle
}

\section{Stimulation Technologies for Deep Well Completions}

\author{
DE-FC26-02NT41663
}

\author{
Technical Progress Report No. 4
}

\author{
04/01/04 - 09/30/04 \\ For: \\ National Energy Technology Laboratory \\ Morgantown, WV
}

By:

Pinnacle Technologies, Inc.

Park North Technology Center

219 Airtex Boulevard

Houston, Texas 77090

\begin{abstract}
This report was prepared as an account of work sponsored by an agency of the United States Government. Neither the United States Government nor any agency thereof, nor any of their employees, makes any warranty, express or implied, or assumes any legal liability or responsibility for the accuracy, completeness, or usefulness of any information, apparatus, product, or process disclosed, or represents that its use would not infringe privately owned rights. Reference herein to any specific commercial product, process, or service by trade name, trademark, manufacturer, or otherwise does not necessarily constitute or imply its endorsement, recommendation or favoring by the United States Government or any agency thereof. The views and opinions of authors expressed herein do not necessarily state or reflect those of the United States Government or any agency thereof.
\end{abstract}

\section{DISCLAIMER}

Neither Pinnacle Technologies, Inc. nor any person acting on behalf of Pinnacle:

- Makes any warranty or representation, express or implied, with respect to the accuracy, completeness, or usefulness of the information contained in this report, or that the use of any apparatus, method or process disclosed in this report may not infringe privately owned rights; or

- Assumes any liability with respect to the use of, or for damages resulting from the use of, any information, apparatus, method or process disclosed in this report 



\section{Abstract}

The Department of Energy (DOE) is sponsoring the Deep Trek Program targeted at improving the economics of drilling and completing deep gas wells. Under the DOE program, Pinnacle Technologies is conducting a study to evaluate the stimulation of deep wells. The objective of the project is to assess U.S. deep well drilling and stimulation activity, review rock mechanics and fracture growth in deep, high pressure/temperature wells, and evaluate stimulation technology in several key deep plays. An assessment of historical deep gas well drilling activity and forecast of future trends was completed during the first six months of the project; this segment of the project was covered in Technical Progress Report No. 1. During the next six months efforts were primarily split between summarizing rock mechanics and fracture growth in deep reservoirs and contacting operators about case studies of deep gas well stimulation as documented in Technical Progress Report No. 2. The case study done with Anadarko and ChevronTexaco in the Table Rock Field in Wyoming was reported in Technical Progress Report No. 3. This report details work done with ConocoPhillips in the Jennings Ranch Field in Texas. 



\section{Table of Contents}

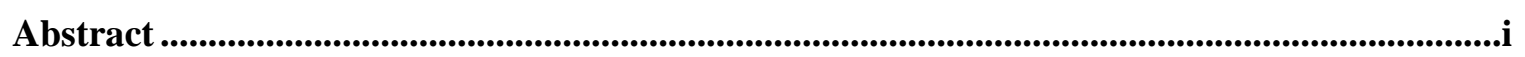

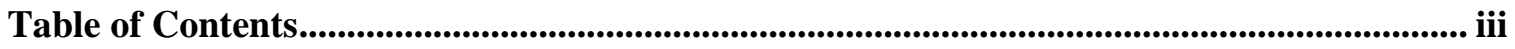

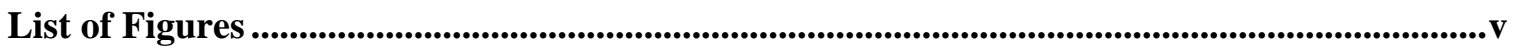

List of Tables..................................................................................................................................................... vii

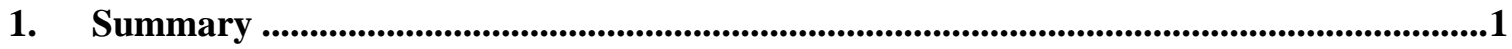

1.1 State-of-the-Art Technology in Deep Formation Stimulation................................1

1.2 Review/Summary of Rock Mechanics and Fracture Growth in Deep

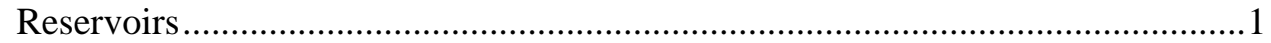

1.3 Fracture Modeling, Production Data Analysis, Reservoir Modeling, and Case

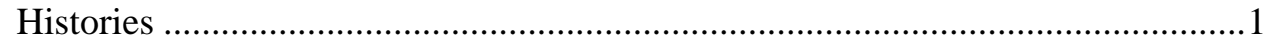

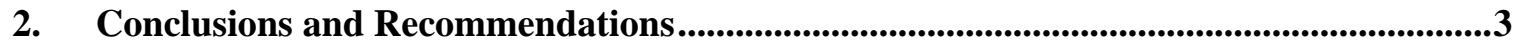

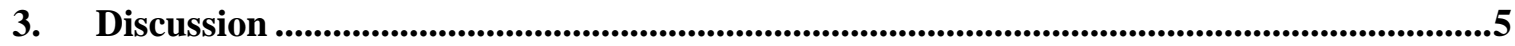

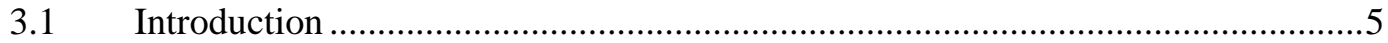

3.2 Fracture Engineering and Production Analysis ...............................................6

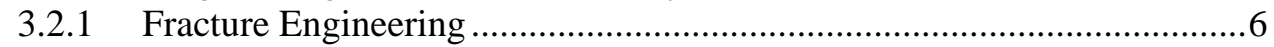

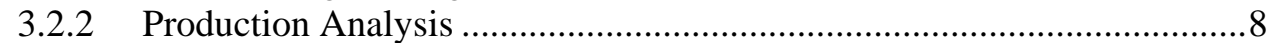

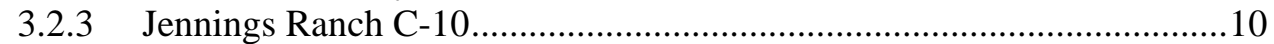

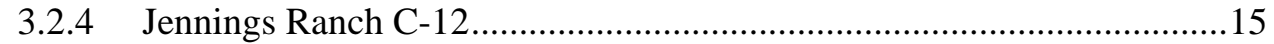

3.2.5 Jennings Ranch C-18......................................................................18

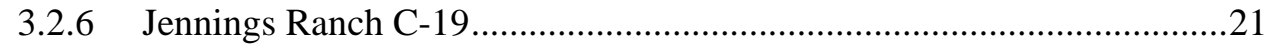

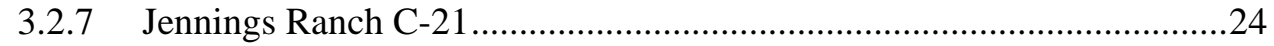

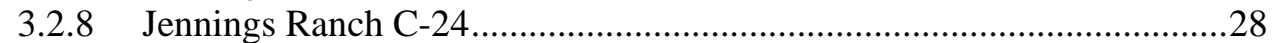

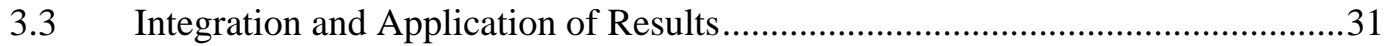

3.3.1 Hydraulic Fracture Optimization.........................................................31 



\section{List of Figures}

Figure 1. Fracture optimization generic well 40 acre spacing....................................................

Figure 2. Fracture optimization generic well 20 acre spacing.....................................................4

Figure 3. Typical well log Jennings Ranch field: Lobo 6 Sand.....................................................5

Figure 4. Field map with study well locations..........................................................................6

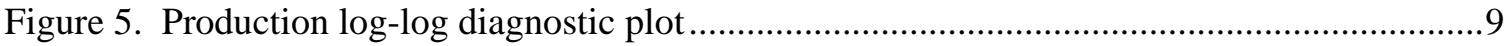

Figure 6. Illustration of fracture complexity: near-wellbore versus far-field ................................10

Figure 7. Treatment data: Jennings Ranch C-10 Lobo 6 ..............................................................11

Figure 8. Closure analysis: Jennings Ranch C-10 Lobo 6 ...........................................................11

Figure 9. Step-down test analysis: Jennings Ranch C-10 Lobo 6 ..............................................12

Figure 10. Net pressure match: Jennings Ranch C-10 Lobo 6 ...................................................12

Figure 11. Model fracture geometry: Jennings Ranch C-10 Lobo 6 ..........................................13

Figure 12. Log-log diagnostic plot of well production: Jennings Ranch C-10 Lobo 6 .................13

Figure 13. Best production match using frac model length and stress-sensitive permeability:

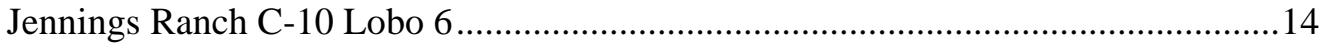

Figure 14. Production match using model frac length and constant permeability: Jennings Ranch C-10 Lobo 6..................................................................................................14

Figure 15. Treatment data: Jennings Ranch C-12 Lobo 6 .........................................................15

Figure 16. Closure analysis: Jennings Ranch C-12 Lobo 6 ........................................................15

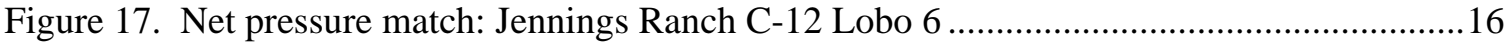

Figure 18. Model fracture geometry: Jennings Ranch C-12 Lobo 6 ..........................................16

Figure 19. Log-log diagnostic plot of well production: Jennings Ranch C-12 Lobo 6 .................17

Figure 20. Production match using model frac length and stress-sensitive permeability: Jennings Ranch C-12 Lobo 6 ..............................................................................17

Figure 21. Treatment data: Jennings Ranch C-18 Lobo 6 ............................................................18

Figure 22. Closure analysis: Jennings Ranch C-12 Lobo 6 .......................................................18

Figure 23. Net pressure match: Jennings Ranch C-18 Lobo 6 ..................................................19

Figure 24. Model fracture geometry: Jennings Ranch C-18 Lobo 6 ….......................................19

Figure 25. Log-log diagnostic plot of well production: Jennings Ranch C-18 Lobo 6 .................20

Figure 26. Production match using model frac length and constant permeability: Jennings Ranch C-18 Lobo 6.................................................................................................20

Figure 27. Treatment data: Jennings Ranch C-19 Lobo 6 ...........................................................21

Figure 28. Closure analysis: Jennings Ranch C-19 Lobo 6 .......................................................22

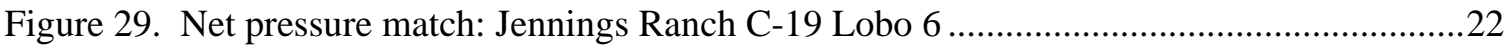

Figure 30. Model fracture geometry: Jennings Ranch C-19 Lobo 6 ..........................................23 
Figure 31. Log-log diagnostic plot of well production: Jennings Ranch C-19 Lobo 6 .23

Figure 32. Production match using model frac length and constant permeability: Jennings Ranch C-19 Lobo 6.

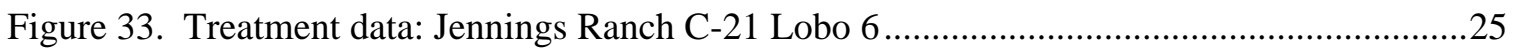

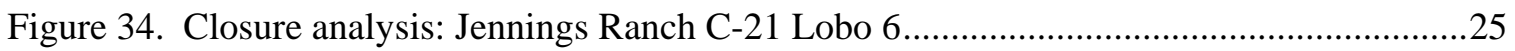

Figure 35. Net pressure match: Jennings Ranch C-21 Lobo 6 ..................................................26

Figure 36. Model fracture geometry: Jennings Ranch C-21 Lobo 6 …......................................26

Figure 37. Log-log diagnostic plot of well production: Jennings Ranch C-21 Lobo 6 .................27

Figure 38. Production match using model frac length and constant permeability: Jennings

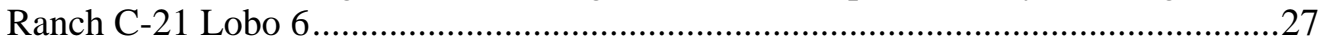

Figure 39. Treatment data: Jennings Ranch C-24 Lobo 6 ............................................................28

Figure 40. Closure analysis: Jennings Ranch C-24 Lobo 6.......................................................29

Figure 41. Net pressure match: Jennings Ranch C-24 Lobo 6 ..................................................29

Figure 42. Model fracture geometry: Jennings Ranch C-24 Lobo 6 ..........................................30

Figure 43. Log-log diagnostic plot of well production: Jennings Ranch C-24 Lobo 6 ..................30

Figure 44. Production match using model frac length and constant permeability: Jennings

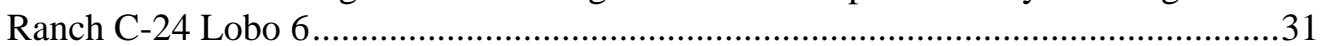

Figure 45. Fracture optimization generic well 80 acre spacing...................................................32

Figure 46. Fracture optimization generic well 40 acre spacing....................................................33

Figure 47. Fracture optimization generic well 20 acre spacing................................................34 


\section{List of Tables}

Table 1. Summary of Fracture Treatments: Diagnostic Injections.............................................. 7

Table 2. Summary of Fracture Treatments: Propped Treatment .................................................... 7

Table 3. Summary of Fracture Analysis Results .................................................................... 8

Table 4. Summary of Production Analysis Results ...................................................................... 9 



\section{Summary}

Pinnacle Technologies (Pinnacle) is performing a study on stimulation for deep well completions as part of the Department of Energy's (DOE) Deep Trek Program. The Department of Energy's (DOE) Deep Trek Program is targeted to improving the economics of drilling and completing deep wells. This project is focused on the second objective of the Deep Trek program, "Improved Economics in Deep Well Completions." The objective of the project is to review current and past stimulation activity and research results for deep well completions and develop information for the industry that will help reduce uncertainty and increase success in frontier and emerging deep formation plays.

The Pinnacle study is focused on three major objectives:

1. Evaluate the current state-of-the-art stimulation technology for deep formations through industry interviews and a comprehensive literature review and assessment

2. Evaluate rock mechanics issues and fracture growth behavior in deep formation completions through literature review, interviews and rock mechanics analysis

3. Perform three to five small case studies evaluating stimulation in key deep formations

This report covers the second six months of the study during which effort was split between wrap up of the first objective and starting efforts on the second and third objectives.

\subsection{State-of-the-Art Technology in Deep Formation Stimulation}

Task 1 consists of a comprehensive review of current literature on stimulation technology for deep formations and interviews with operators, service companies and consultants. The result will be documentation of stimulation and completion practices in major deep formations and the identification of operator and service company technical requirements. Results of this work were documented in previous reports.

\subsection{Review/Summary of Rock Mechanics and Fracture Growth in Deep Reservoirs}

Task 2 consists of an evaluation of the rock mechanics issues and fracture growth behavior in deep formations. Results of this work were documented in previous reports.

\subsection{Fracture Modeling, Production Data Analysis, Reservoir Modeling, and Case Histories}

Task 3 consists of an evaluation of stimulation in three to five deep gas formations identified in Task 1 . The focus of the evaluations will be the integration of fracture modeling and production data analyses to better understand fracture performance. Based on the activity levels forecast in Task 1 and resource potential in each region, NETL has selected key regions for consideration for further study. For each major deep gas region five to ten of the most active operators were contacted about participating in a study. Case study partners were identified for three areas:

- ConocoPhillips - Jennings Ranch Field in South Texas

- Anadarko and ChevronTexaco - Table Rock Field in Wyoming 


\section{- Marathon - Several wells in Oklahoma}

This report covers work performed with ConocoPhillips. This study focused on a deep gas productive horizon operated by ConocoPhillips in the Jennings Ranch Field, Zapata County, Texas. The primary targets are the Lobo 6, Lobo 1 and Lobo Stray sands. This study focused on the deeper Lobo 6 interval at depths of roughly 12,200 feet to 12,500 feet. The formation is highly over-pressured with pressures of about $10,200 \mathrm{psi}(0.81 \mathrm{psi} / \mathrm{ft})$ and fracturing pressures of about $0.93 \mathrm{psi} / \mathrm{ft}$ to $0.96 \mathrm{psi} / \mathrm{ft}$. Porosities are about $16 \%$ to $21 \%$ with water saturations of $45 \%$ to $55 \%$. Net pay can vary from about 20 feet to over 100 feet. All wells are completed with crosslinked gel fracture treatments using ceramic proppants. Multiple target zones are generally commingled, with a typical well producing about 7 to 8 MMCFD initially, and declining fairly fast to 2 MMCFD or less within one year. The wells are located in 80 to 120 acre fault blocks with three to four wells per fault block (20 acre to 40 acre well spacing). Approximately sixty to seventy wells were drilled over the last five years. The study included a total of six wells drilled and completed from 1999 to 2001.

The main conclusions are that modeled propped fracture lengths are approximately 400 to 660 feet, with fracture heights slightly larger than the perforated interval. Fracture treatments do not show any obvious problems with fracture length generation or proppant placement. Production analysis, although somewhat non-unique, indicates that effective fracture lengths could be as long as the ones calculated with the fracture model.

All wells show fairly rapid production declines, which is normal in highly over-pressured reservoirs with fracture stimulation; however, two wells showed higher production declines, which may indicate an impairment of either reservoir or fracture flow capacity since production could not be modeled with constant reservoir/fracture properties. It is not clear if the impairment was caused due to stress-sensitive reservoir permeability (high drawdowns) or a deteriorating hydraulic fracture (reduced proppant conductivity due to higher effective stress, fines migration into proppant pack, multi-phase flow). Flow tests with bottomhole gauges followed by pressure buildup tests could be used to diagnose if the problem is due to a deteriorating hydraulic fracture.

Production data shows reservoir linear flow for about one to two years indicating effective fracture stimulation. This period is followed by the onset of a depletion stem, which could be limited drainage from offset wells, geology and/or liquid loading conditions. Estimated drainage areas highly depend on assumptions of hydrocarbon pore volume (porosity, net pay, water saturation) but, using the numbers provided by the operator, drainage areas were estimated to range from as low as seven acres to about 70 acres.

The biggest opportunity in this drilling program appears to be fracture optimization as a function of actual well spacing. Preliminary generic optimization simulations show the potential for job size reductions as well spacing is reduced. It also indicates that current job sizes may be close to the optimum if well spacing is around 40 acres but for fault blocks with well spacing smaller than 40 acres job sizes could potentially be reduced. 


\section{Conclusions and Recommendations}

1. Propped fracture lengths are modeled to be approximately 400 to 660 feet, with fracture heights slightly larger than the perforated interval. Fracture treatments did not encounter any problems, and do not show any obvious problems with fracture length generation or proppant placement. These model geometries have not been confirmed with actual fracture geometry measurements such as microseismic and tiltmeter fracture mapping. Production analysis, although somewhat non-unique, indicates that effective fracture lengths could be as long as the ones calculated with the fracture model.

2. Moderate fracture complexity was observed on most treatments but does not seem to play a major role in proppant placement or severe reduction of fracture length. Estimates of actual fracture conductivities are difficult and limited by both fracture complexity issues and actual effective conductivities under flowing conditions; however, based on initial production and its decline, four out of six wells show no evidence that fracture conductivities have been severely impaired in the first year of production.

3. All wells show fairly rapid production declines, which is normal in highly over-pressured reservoirs with fracture stimulation; however, in two wells (C-10 and C-12) production declines were too high, which may indicate an impairment of either reservoir or fracture flow capacity since production could not be modeled with constant reservoir/fracture properties. It is not clear if the impairment was caused due to stress-sensitive reservoir permeability (high drawdowns) or a deteriorating hydraulic fracture (reduced proppant conductivity due to higher effective stress, fines migration into proppant pack, multiphase flow; note: these two wells were stimulated with Econoprop). If possible, single zone flow tests followed by a pressure buildup test could be used to diagnose if the problem is in fact due to a deteriorating hydraulic fracture or is simply a stress-sensitive reservoir permeability issue.

4. Production analysis indicates that all wells have some degree of reservoir linear flow behavior once clean-up effects have subsided and wells are flowed at fairly constant flowing pressures. The linear flow regime lasts about one year to two years in most wells, indicating effective fracture stimulation. This period is followed by the onset of a depletion stem, which could be limited drainage from offset wells, geology and/or liquid loading conditions. Estimated drainage areas highly depend on assumptions of hydrocarbon pore volume (porosity, net pay, water saturation) but using the numbers provided by the operator were estimated to range from as low as 7 acres to 70 acres with flow capacity (kh) ranging from about $0.1 \mathrm{md}-\mathrm{ft}$ to $4 \mathrm{md}-\mathrm{ft}$.

5. Fracture optimization depends heavily on well spacing and reservoir properties such as permeability. Generic fracture optimization simulations show that the 80 -acre spacing optimum frac size is about $420 \mathrm{klb}$, for 40 -acre spacing the optimum size decreases to about $240 \mathrm{klb}$ (which is close to current designs - Figure 1), and for continued infill drilling to 20 acre spacing, optimum size would decrease to about $130 \mathrm{klb}$ (Figure 2). These simulations were performed for a representative set of reservoir properties and economic assumptions that may require some fine-tuning but were done to demonstrate the importance of fracture optimization for infill drilling. 


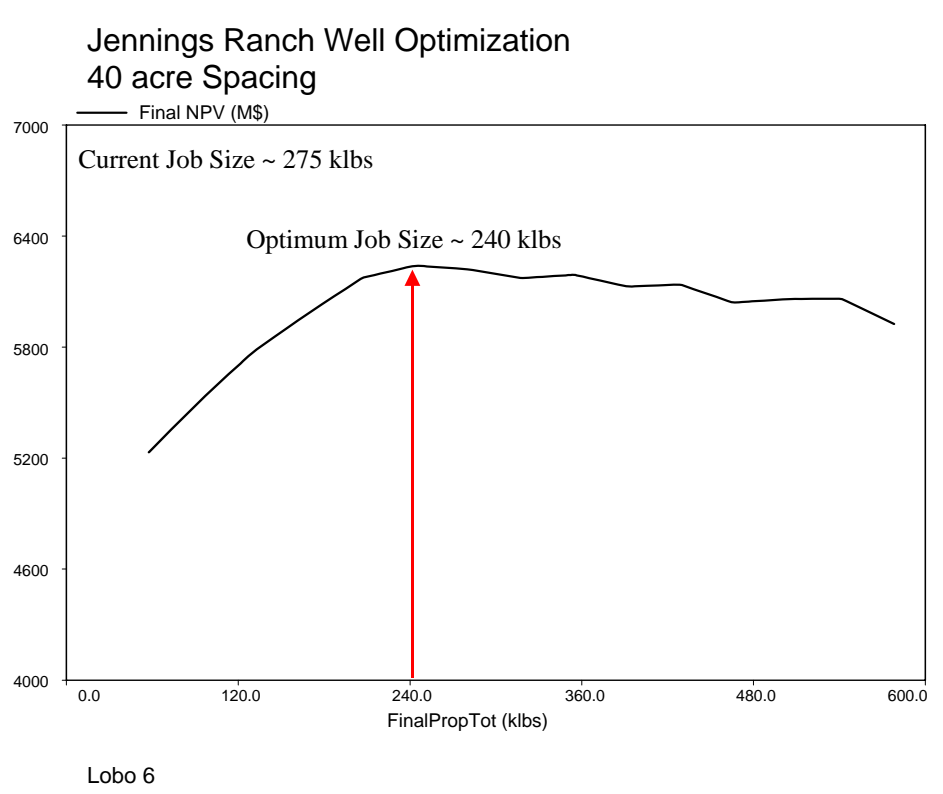

Figure 1. Fracture optimization generic well 40 acre spacing

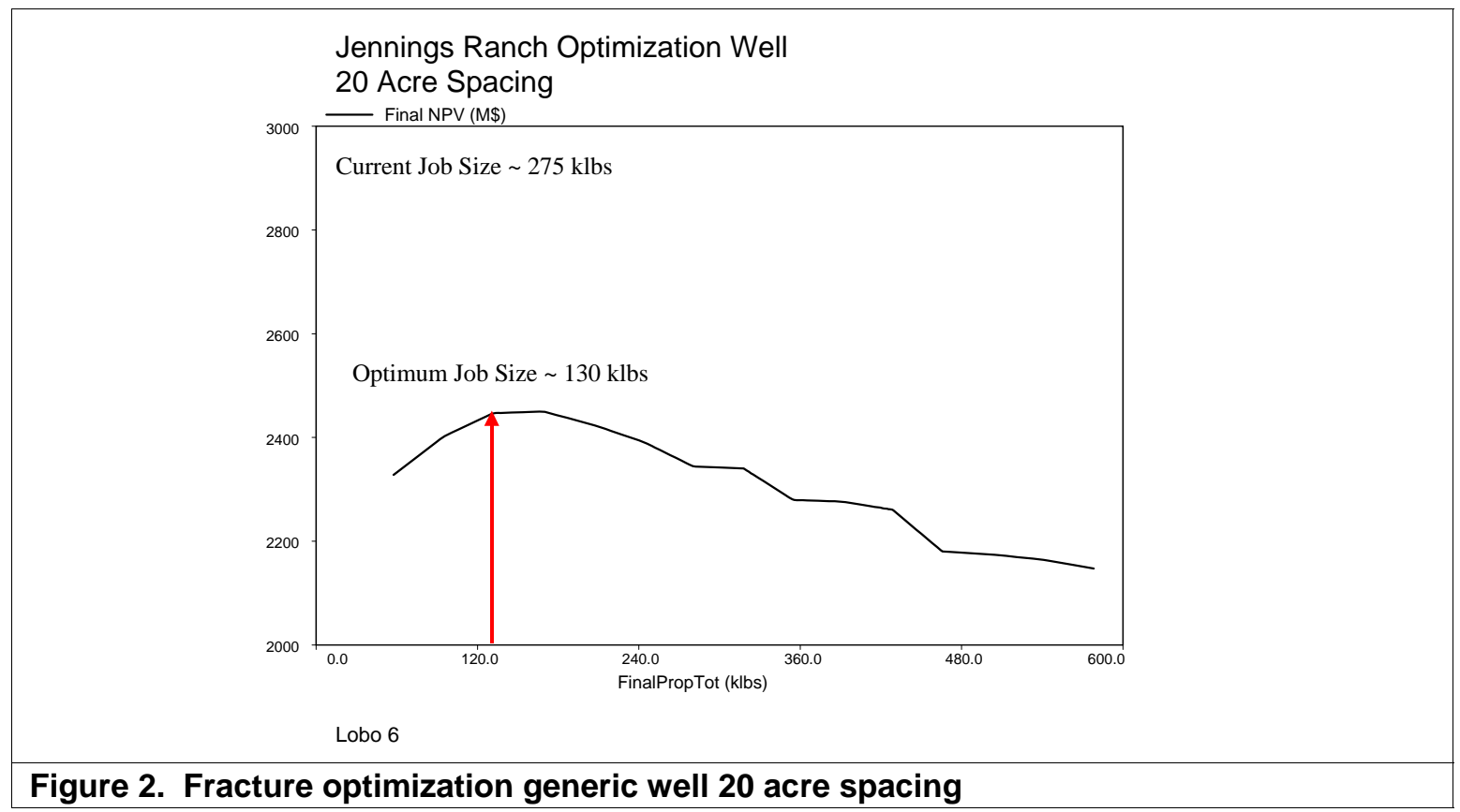




\section{Discussion}

\subsection{Introduction}

This study focused on a deep gas productive horizon operated by ConocoPhillips in the Jennings Ranch Field, Zapata County, South Texas. The primary targets are the Lobo 6, Lobo 1 and Stray sands. This study focused on just the deeper Lobo 6 interval at depths of roughly 12,200 feet to 12,500 feet. The formation is highly over-pressured with pressures of about 10,200 psi $(0.82$ psi/ft). Porosities are about $16 \%$ to $21 \%$ with water saturations of $45 \%$ to $55 \%$. Net pay can vary from about 20 feet to over 100 feet. All wells are completed with crosslinked gel fracture treatments using ceramic proppants. Multiple target zones are generally commingled, with a typical well producing about 7 to 8 MMCFD initially, and declining fairly fast to 2 MMCFD or less within one year. The wells are located in 80 to 120 acre fault blocks with three to four wells per fault block. Approximately sixty to seventy wells were drilled over the last five years.

The study included a total of six wells drilled and completed from 1999 to 2001 . Figure 3 shows a typical log section of the Lobo 6 interval and Figure 4 is a field map showing the study wells (designated by red arrows).

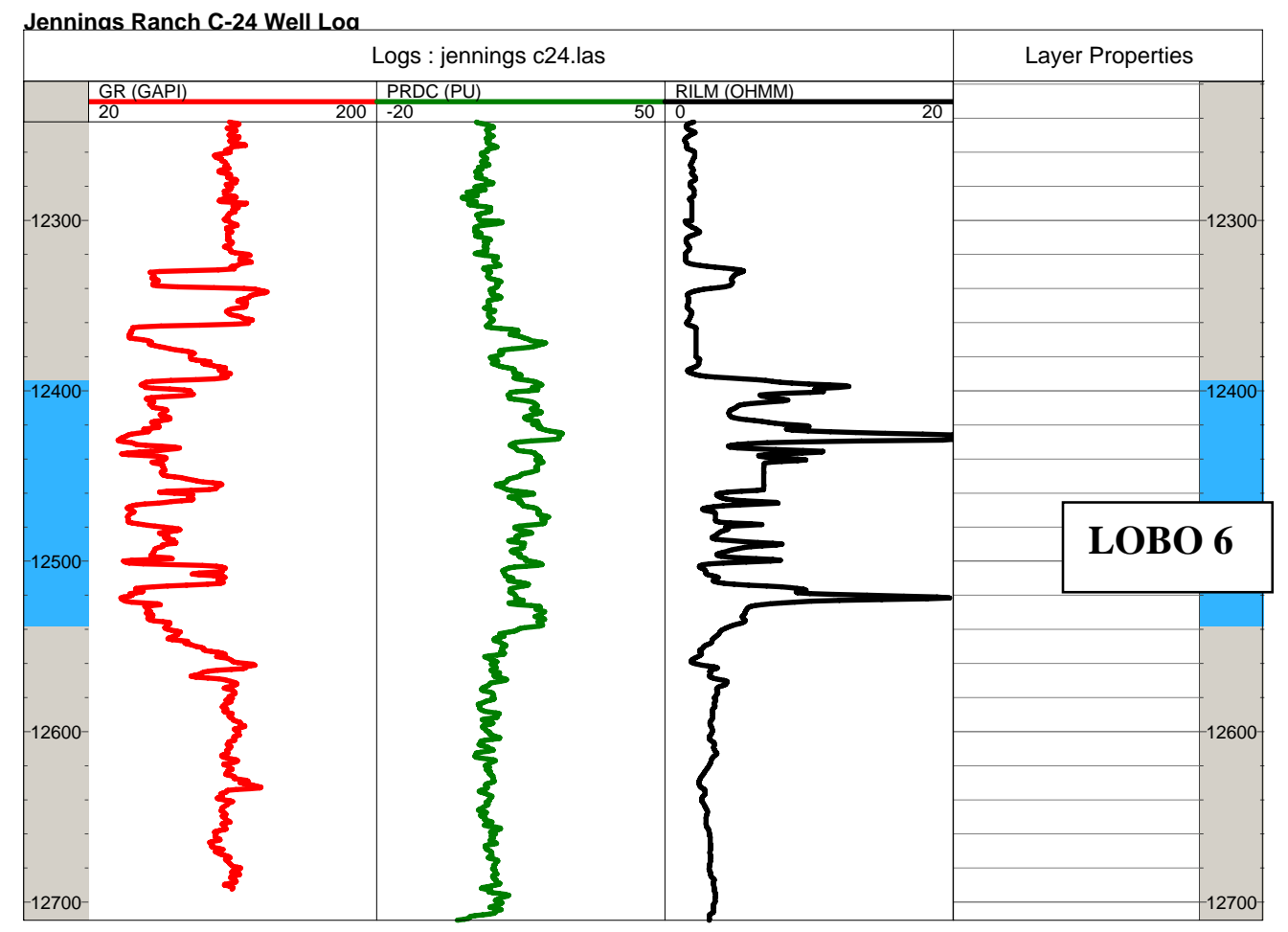

Figure 3. Typical well log Jennings Ranch field: Lobo 6 Sand 


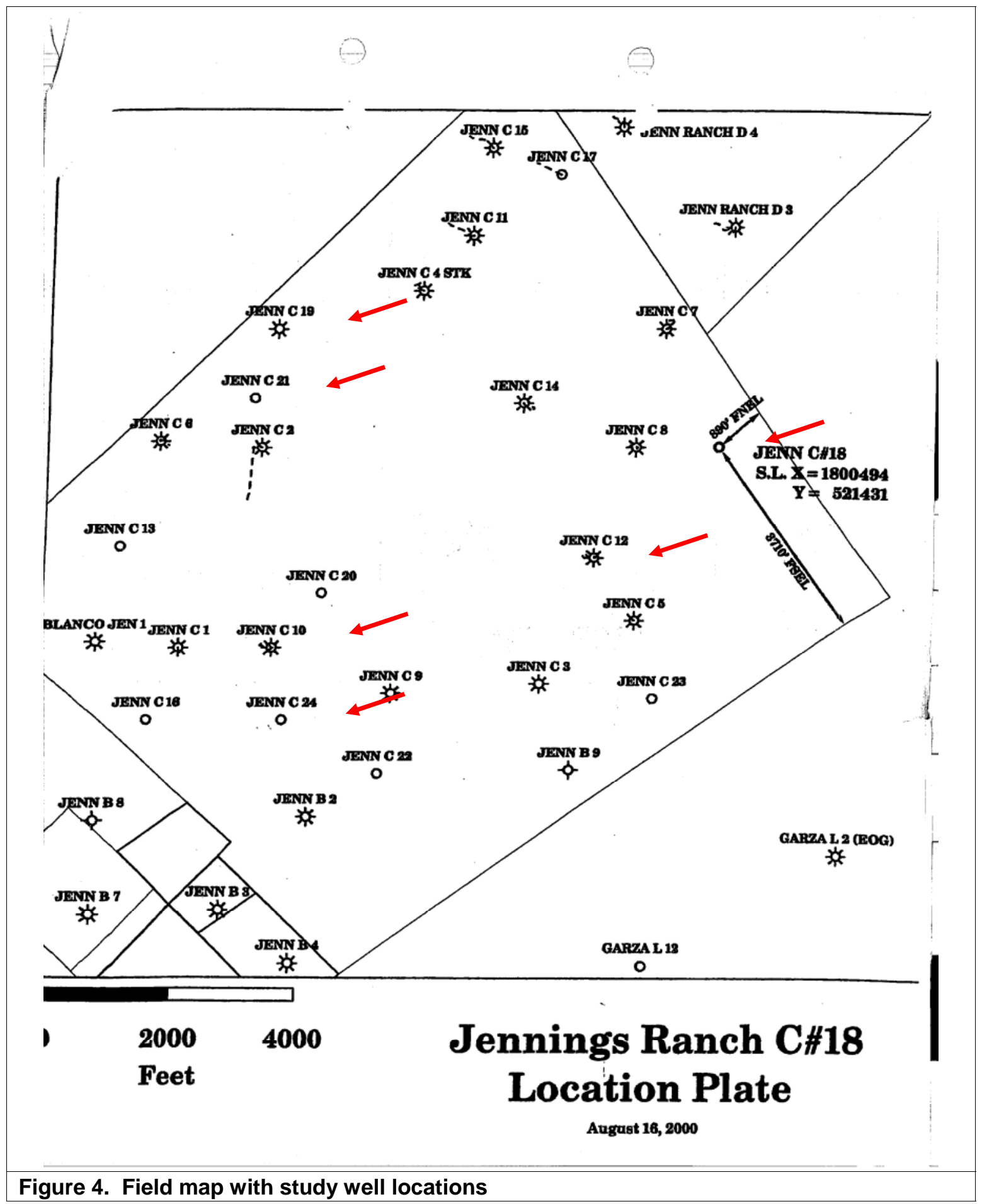

\subsection{Fracture Engineering and Production Analysis}

\subsubsection{Fracture Engineering}

A total of six Lobo 6 treatments in six wells were analyzed in this study. Table 1 and Table 2 summarize the most important fracturing treatment information from all study wells. Fracture closure pressure was only measured in the Jennings Ranch C-10 (0.87 psi/ft). ISIPs generally fall 
between $0.93 \mathrm{psi} / \mathrm{ft}$ to $0.96 \mathrm{psi} / \mathrm{ft}$ for both the mini-fracs and main treatments. Assuming 0.87 $\mathrm{psi} / \mathrm{ft}$ closure stress in all other wells, fracturing net pressures are between $750 \mathrm{psi}$ to 1,000 psi for the mini-fracs with a fairly low increase of 10 psi to 300 psi during the main treatment. This indicates that current fracture treatment designs and completion methodologies are successful in placing jobs without any major pressure increases.

Four treatments were pumped using 20/40 Econoprop (lowest strength ceramic proppant) and two with a higher strength 20/40 Carboprop (C-21 and C-24). Fracturing fluids were 50 to $60 \mathrm{lb} / \mathrm{Mgal}$ crosslinked gels, tapered off to a 35-lb/Mgal system at the end of the treatment. Maximum proppant concentrations were 5 to $6 \mathrm{ppg}$ with total job sizes being about 270 to $430 \mathrm{klb}$ of proppant depending on gross zone thickness. Pump rate was about $40 \mathrm{bbl} / \mathrm{min}$ and total slurry volume about 2,400 bbl to $3,500 \mathrm{bbl}$ with pad sizes of $25 \%$ to $30 \%$.

Table 1. Summary of Fracture Treatments: Diagnostic Injections

\begin{tabular}{|c|c|c|c|c|c|c|c|c|c|}
\hline Well & \multirow{2}{*}{ Zone } & $\begin{array}{c}\text { Top Perf } \\
\text { MD } \\
\text { (ft) }\end{array}$ & $\begin{array}{c}\text { Btm Perf } \\
\text { MD } \\
\text { (ft) }\end{array}$ & $\begin{array}{c}\text { Cls P } \\
\text { psi }\end{array}$ & $\begin{array}{c}\text { Eff } \\
(\%)\end{array}$ & $\begin{array}{c}\text { Cls Grd } \\
\text { psi/ft }\end{array}$ & $\begin{array}{c}\text { ISIP(BH) } \\
\text { psi }\end{array}$ & $\begin{array}{c}\text { ISIP Grd } \\
\text { psi/ft }\end{array}$ & $\begin{array}{c}\text { Net P } \\
\text { psi }\end{array}$ \\
\hline C-10 & L6 & 12201.0 & 12350.0 & 10709 & $30 \%$ & 0.87 & 11451 & 0.93 & 742 \\
\hline C-12 & L6 & 12494.0 & 12617.0 & n.a. & n.a. & n.a. & 11829 & 0.94 & 798 \\
\hline C-18 & L6 & 12220.0 & 12360.0 & n.a. & n.a. & n.a. & 11565 & 0.94 & 851 \\
\hline C-19 & L6 & 12253.0 & 12431.0 & n.a. & n.a. & n.a. & 11786 & 0.95 & 1009 \\
\hline C-21 & L6 & 12496.0 & 12744.0 & n.a. & n.a. & n.a. & 11728 & 0.93 & 748 \\
\hline C-24 & L6 & 12394.0 & 12538.0 & n.a. & n.a. & n.a. & 11855 & 0.95 & 961 \\
\hline
\end{tabular}

Table 2. Summary of Fracture Treatments: Propped Treatment

\begin{tabular}{|c|c|c|c|c|c|c|c|c|c|c|c|c|}
\hline \multirow[b]{2}{*}{ Well } & \multirow[b]{2}{*}{ Zone } & \multirow{2}{*}{$\begin{array}{c}\text { Top Perf } \\
\text { MD } \\
\text { (ft) }\end{array}$} & \multirow{2}{*}{$\begin{array}{c}\text { Btm Perf } \\
\text { MD } \\
\text { (ft) }\end{array}$} & \multicolumn{9}{|c|}{ Propped Treatment Summary } \\
\hline & & & & $\begin{array}{c}\text { Vol } \\
\text { bbls }\end{array}$ & \begin{tabular}{|c|} 
Rate \\
bbls $/ \mathrm{min}$
\end{tabular} & $\begin{array}{l}\text { Prop } \\
\text { klbs }\end{array}$ & $\begin{array}{c}\text { ISIP(BH) } \\
\text { psi }\end{array}$ & \begin{tabular}{|c|} 
ISIP Grad \\
psi
\end{tabular} & $\begin{array}{c}\text { Net P } \\
\text { psi }\end{array}$ & $\begin{array}{c}\text { Screen } \\
\text { Out? }\end{array}$ & $\begin{array}{c}\text { Net P Increase } \\
\text { psi }\end{array}$ & Comments \\
\hline $\mathrm{C}-10$ & L6 & 12201.0 & 12350.0 & 3425.0 & 40.0 & 426 & 11746 & 0.96 & 1037 & $\mathrm{n}$ & 295 & Econoprop 20/40; YF850-835 \\
\hline $\mathrm{C}-12$ & L6 & 12494.0 & 12617.0 & 2527.0 & 36.0 & 276 & 11852 & 0.94 & 821 & $\mathrm{n}$ & 23 & Econoprop 20/40; Med 60\# to Med 40\# \\
\hline C-18 & L6 & 12220.0 & 12360.0 & 2464.0 & 40.0 & 283 & 11575 & 0.94 & 861 & $\mathrm{n}$ & 10 & Econoprop 20/40; Med 45\# to Med 35\# \\
\hline C-19 & L6 & 12253.0 & 12431.0 & 3197.0 & 40.0 & 350 & 11852 & 0.96 & 1075 & $\mathrm{n}$ & 66 & Econoprop 20/40; Med 50\# to Med 35\# \\
\hline $\mathrm{C}-21$ & L6 & 12496.0 & 12744.0 & 3220.0 & 45.0 & 400 & 11896 & 0.94 & 916 & $\mathrm{n}$ & 168 & Carboprop 20/40; Med 50\# to Med 35\# \\
\hline $\mathrm{C}-24$ & L6 & 12394.0 & 12538.0 & 3039.0 & 43.0 & 365 & 11911 & 0.96 & 1017 & $\mathrm{n}$ & 56 & Carboprop 20/40; Med 50\# to Med 35\# \\
\hline
\end{tabular}

Table 3 shows a summary of the fracture modeling results. All fracture modeling was performed using the 3-dimensional hydraulic frac simulator FracproPT. Fracturing net pressures were fairly high, indicating some degree of far-field fracture complexity (multiple fractures), which could limit fracture extent (Figure 6). The last column of Table 3 summarizes the fracture complexity settings. These numbers are not meant to be exact representations of the number of multiple fracture branches but indicate that the degree of complexity is moderate in four wells and two wells had no meaningful complexity (C-12 and C-18). Near-wellbore fracture complexity (tortuosity) was fairly low on all treatments, indicating no fracture width problems for proppant as it enters the fracture. 
Table 3. Summary of Fracture Analysis Results

\begin{tabular}{|c|c|c|c|c|c|c|c|}
\hline Well & Zone & $\begin{array}{c}\text { Top Perf MD } \\
\text { (ft) }\end{array}$ & $\begin{array}{c}\text { Btm Perf MD } \\
\text { (ft) }\end{array}$ & $\begin{array}{c}\text { Prop Length } \\
\mathbf{f t}\end{array}$ & $\begin{array}{c}\text { Prop Height } \\
\text { ft }\end{array}$ & $\begin{array}{c}\text { Conductivity (frac system) } \\
\text { md-ft }\end{array}$ & $\begin{array}{c}\text { Multiple Fracture Settings } \\
\text { Volume-Leakoff-Opening }\end{array}$ \\
\hline C-10 & L6 & 12201.0 & 12350.0 & 405 & 178 & 2115 & $3-3-3$ \\
\hline C-12 & L6 & 12494.0 & 12617.0 & 603 & 221 & 451 & $1-1-1$ \\
\hline C-18 & L6 & 12220.0 & 12360.0 & 663 & 204 & 353 & $1-1-1$ \\
\hline C-19 & L6 & 12253.0 & 12431.0 & 419 & 223 & 820 & $5-4-5$ \\
\hline C-21 & L6 & 12496.0 & 12744.0 & 510 & 235 & 1568 & $2-3-2$ \\
\hline C-24 & L6 & 12394.0 & 12538.0 & 431 & 207 & 1752 & $4-4-4$ \\
\hline
\end{tabular}

Modeled propped fracture lengths are estimated to be about 400 to 660 feet with propped fracture heights between $175 \mathrm{ft}$ and $235 \mathrm{ft}$ showing some limited growth above and below the target interval but all-in-all fairly contained. Conductivities in Table 3 are ideal values and do not account for non-darcy and multi-phase flow corrections and assume that multiple fracture branch conductivity is additive. Fracture model results have not been verified with independent far-field fracture diagnostics such as microseismic or tiltmeter fracture mapping since it has not yet been done in deeper, hotter South Texas environments.

\subsubsection{Production Analysis}

Table 4 summarizes the production analysis results for all six wells. The C-10 was the only well that produced the Lobo 6 by itself for three years. All other wells were immediately commingled with Lobo 1 sand above. The allocation of production to the Lobo 6 sand used in the analysis was provided by ConocoPhillips using production logs where available and bulk volume of hydrocarbons. All wells except the C-12 (only 17\%), have a Lobo 6 contribution of over 50\% (56\% to $72 \%$ ). Net pay, porosity and water saturation estimates were provided by ConocoPhillips. The production analysis was performed using a single-phase, single-layer numerical reservoir simulator in FracproPT ${ }^{\mathrm{TM}}$. Non-darcy and multi-phase flow effects (assuming $10 \mathrm{bbl} / \mathrm{MMCF}$ liquid yield), and proppant embedment, were included in the simulation. Drainage area shape was assumed to be rectangular with the extent in the frac direction being slightly longer than the fracture length.

Graphs of the production analysis are presented in the following section under each individual well. It includes a log-log diagnostic plot of production versus time and a match of flowing pressures (production rates were used as input constraint in simulations). The plots indicate that all wells have some degree of reservoir linear flow behavior once cleanup effects have subsided and wells are flowed at fairly constant flowing pressures. The linear flow regime appears to last about one year to two years in most wells, followed by the onset of a depletion stem, which could be limited drainage from offset wells, geology and/or liquid loading conditions (Figure 5). Production analysis can be non-unique to some extent but in this case the use of the fracture model lengths appears to result in reasonable matches; however, production declines are fairly rapid, which is common in tight over-pressured reservoirs and is also an indication of reasonable fracture stimulation but in some cases (C-10 and C-12 wells) the decline was more than can be modeled with constant reservoir or fracture properties (Figure 13 and Figure 14). In those cases the simulations were performed by reducing reservoir permeability by $75 \%$ as a function of effective stress (stress-sensitive permeability can occur in over-pressured reservoirs with large drawdowns). Of course, the reason for rapid declines could also be caused by a deteriorating hydraulic fracture (such as fines migration into the proppant pack, stress-sensitive behavior of frac conductivity, and multi-phase flow inside the fracture). These effects cannot be distinguished from production analysis alone. Other tests such as pressure transient tests combining a drawdown with a buildup could be used to evaluate hydraulic fracture quality. 
Production analysis results in Table 4 show a wide range of formation flow capacity (kh) ranging from less than $0.1 \mathrm{md}-\mathrm{ft}(\mathrm{C}-10)$ to almost $4 \mathrm{md}-\mathrm{ft}(\mathrm{C}-21)$ with drainage areas between 7 acres and 70 acres. Of course these results highly depend on the assumptions of net pay, porosity and water saturations.

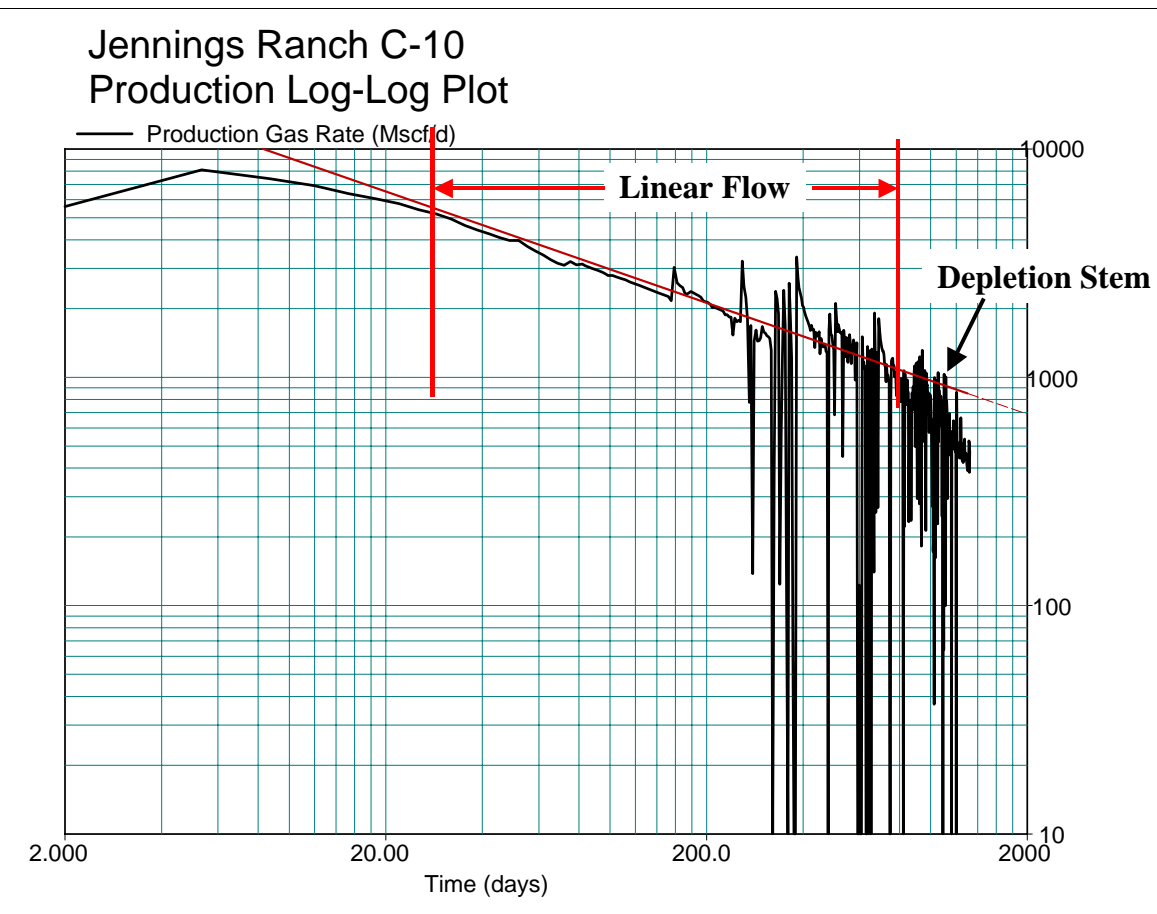

Lobo 6

12-8-1999

Figure 5. Production log-log diagnostic plot

Table 4. Summary of Production Analysis Results

\begin{tabular}{|c|c|c|c|c|c|c|c|c|c|}
\hline Well & Zone & Top Perf MD & $\begin{array}{c}\text { Btm Perf } \\
\text { MD } \\
\text { (ft) }\end{array}$ & $\begin{array}{c}\text { Net Pay } \\
\mathbf{f t}\end{array}$ & $\begin{array}{c}\text { Porosity } \\
\%\end{array}$ & $\begin{array}{c}\text { Sw } \\
\%\end{array}$ & $\begin{array}{c}\text { k } \\
\text { md }\end{array}$ & $\begin{array}{c}\text { kh } \\
\text { md-ft }\end{array}$ & $\begin{array}{c}\text { DA } \\
\text { acres }\end{array}$ \\
\hline C-10 & L6 & 12201.0 & 12350.0 & 40 & 17 & 54 & 0.0900 & 3.60 \\
\hline C-12 & L6 & 12494.0 & 12617.0 & 17 & 15 & 56 & 0.0400 & 0.68 & 54 \\
\hline C-18 & L6 & 12220.0 & 12360.0 & 60 & 18 & 56 & 0.0150 & 0.90 & 45 \\
\hline C-19 & L6 & 12253.0 & 12431.0 & 125 & 21 & 46 & 0.0014 & 0.18 & 10 \\
\hline C-21 & L6 & 12496.0 & 12744.0 & 114 & 16 & 52 & 0.00038 & 0.043 & 7 \\
\hline C-24 & L6 & 12394.0 & 12538.0 & 94 & 16 & 49 & 0.0065 & 0.61 & 16 \\
\hline
\end{tabular}




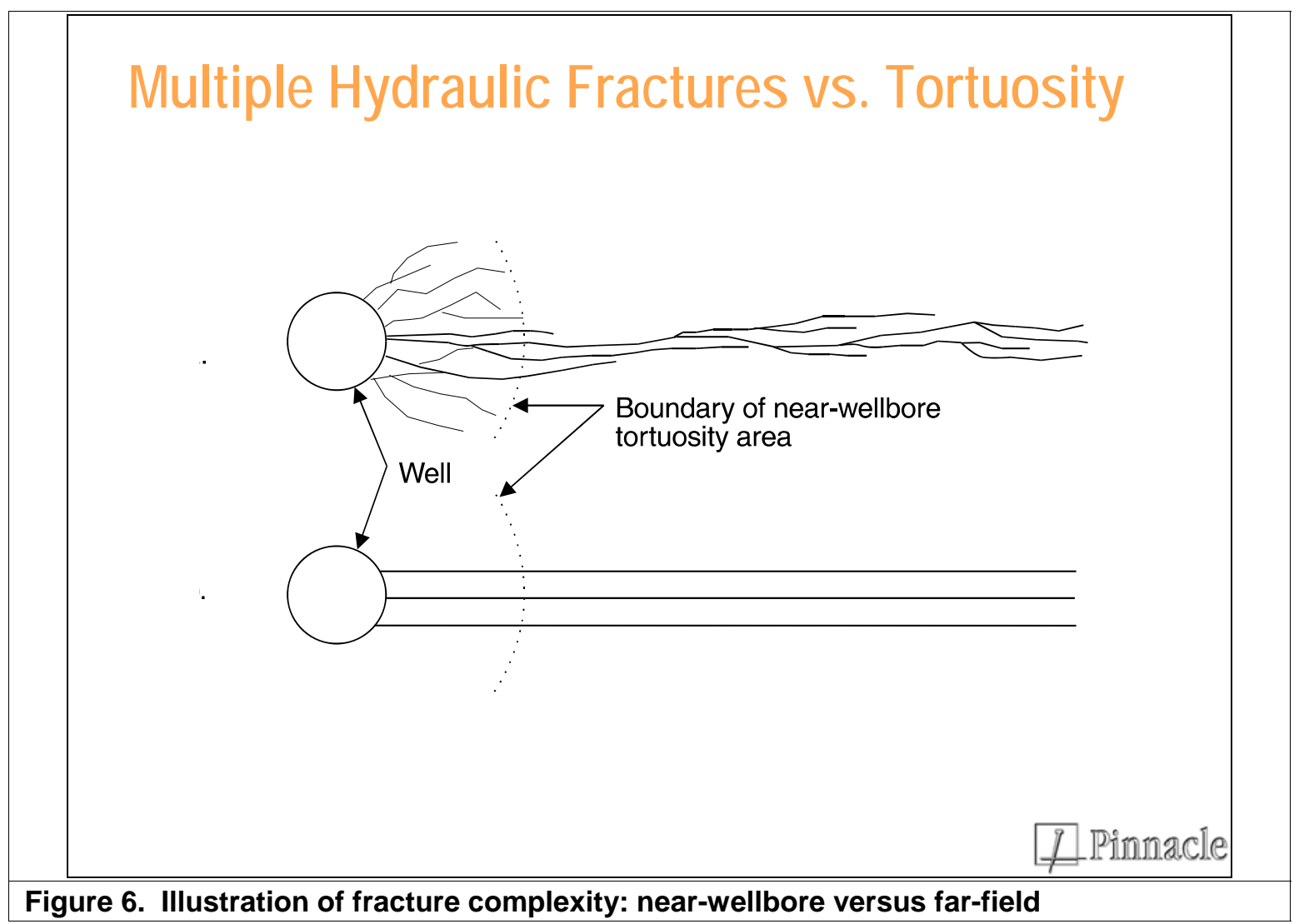

The following section details all the individual fracture treatments with graphs of treatment data, fracture closure analysis, net pressure matches and resulting fracture geometry along with the production analysis plots.

\subsubsection{Jennings Ranch C-10}

The C-10 treatment was the only treatment where the mini-frac reached closure pressure. It was estimated to be about $0.87 \mathrm{psi} / \mathrm{ft}$ (Figure 8). Figure 9 shows that near-wellbore tortuosity and perforation friction are fairly low (190 psi near-wellbore and 100 psi perforation friction at 25 bpm). The net pressure match is shown in Figure 10. Fracture length is estimated to be about 450 $\mathrm{ft}$ with fracture height slightly more than the perforated interval. The production match in Figure 13 and Figure 14 show how stress-sensitive permeability improves the quality of the flowing pressure match. 


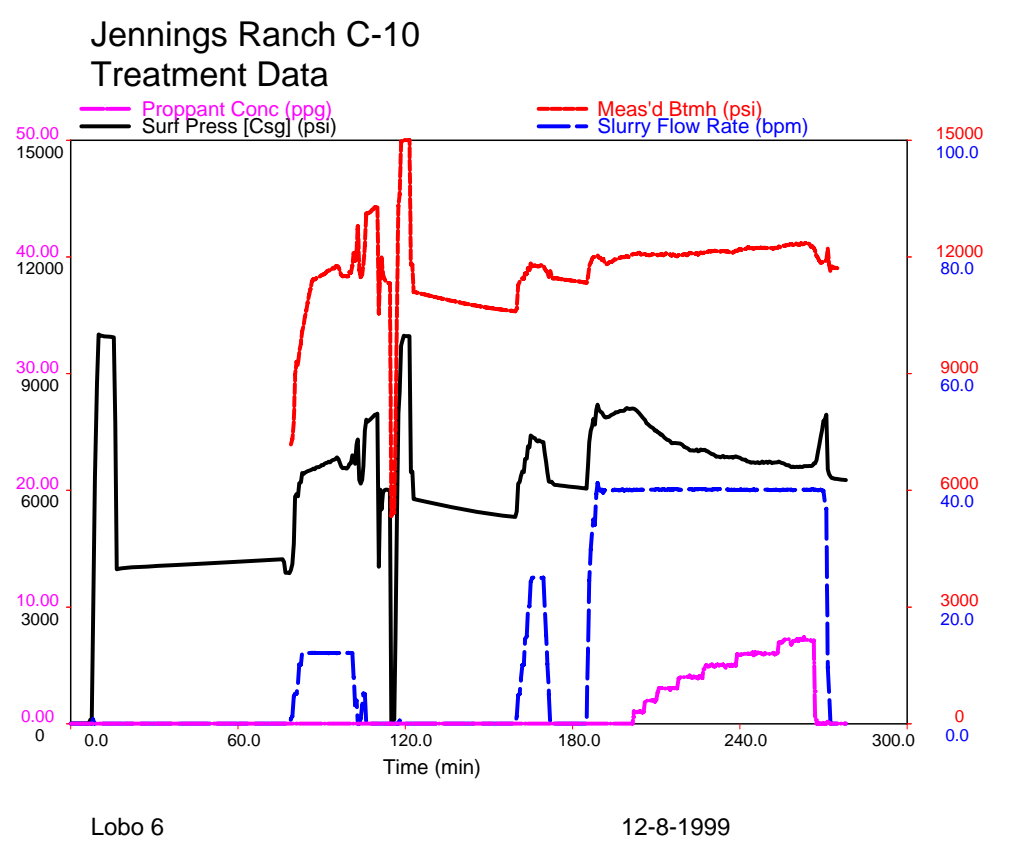

Figure 7. Treatment data: Jennings Ranch C-10 Lobo 6

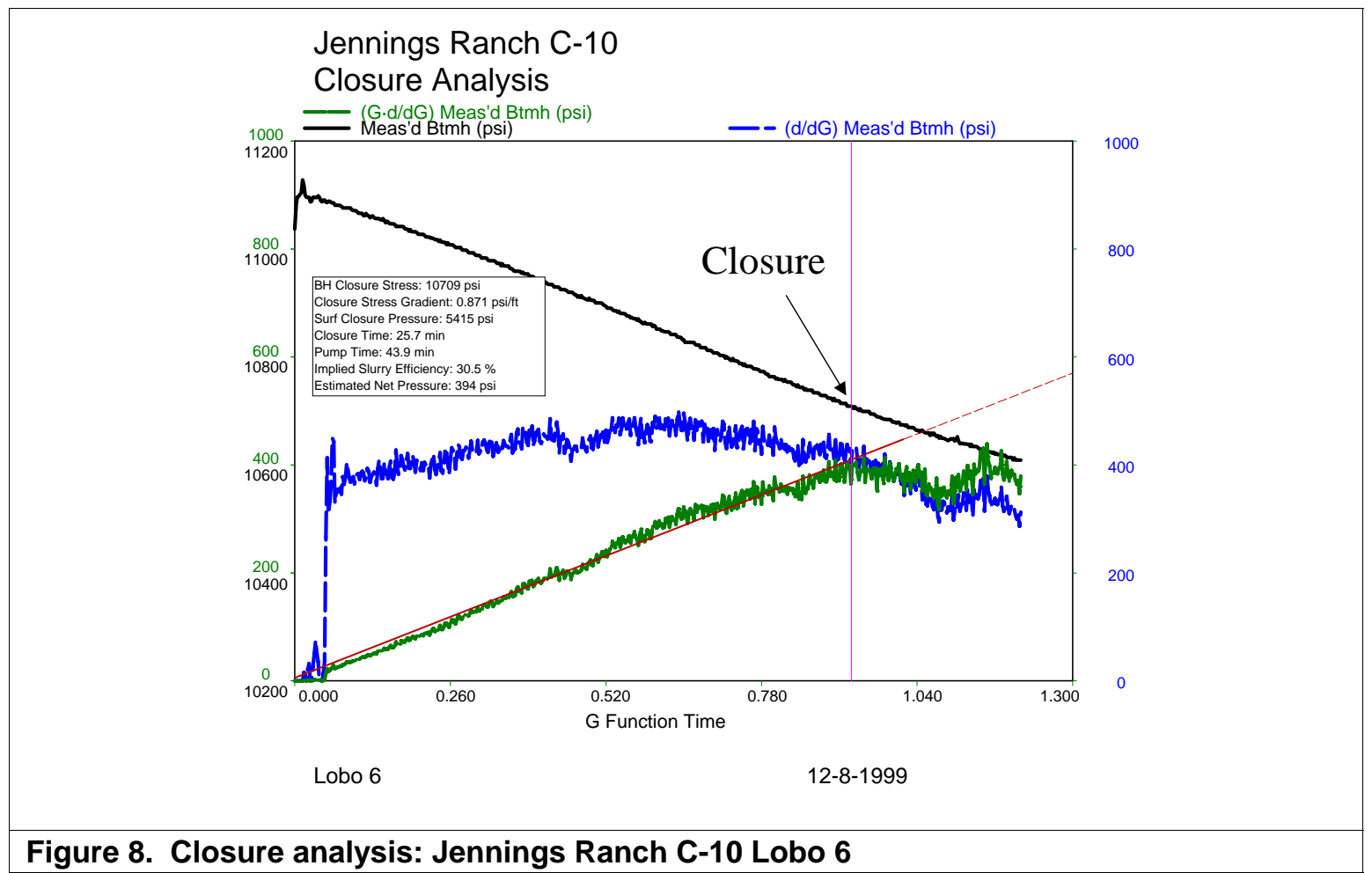



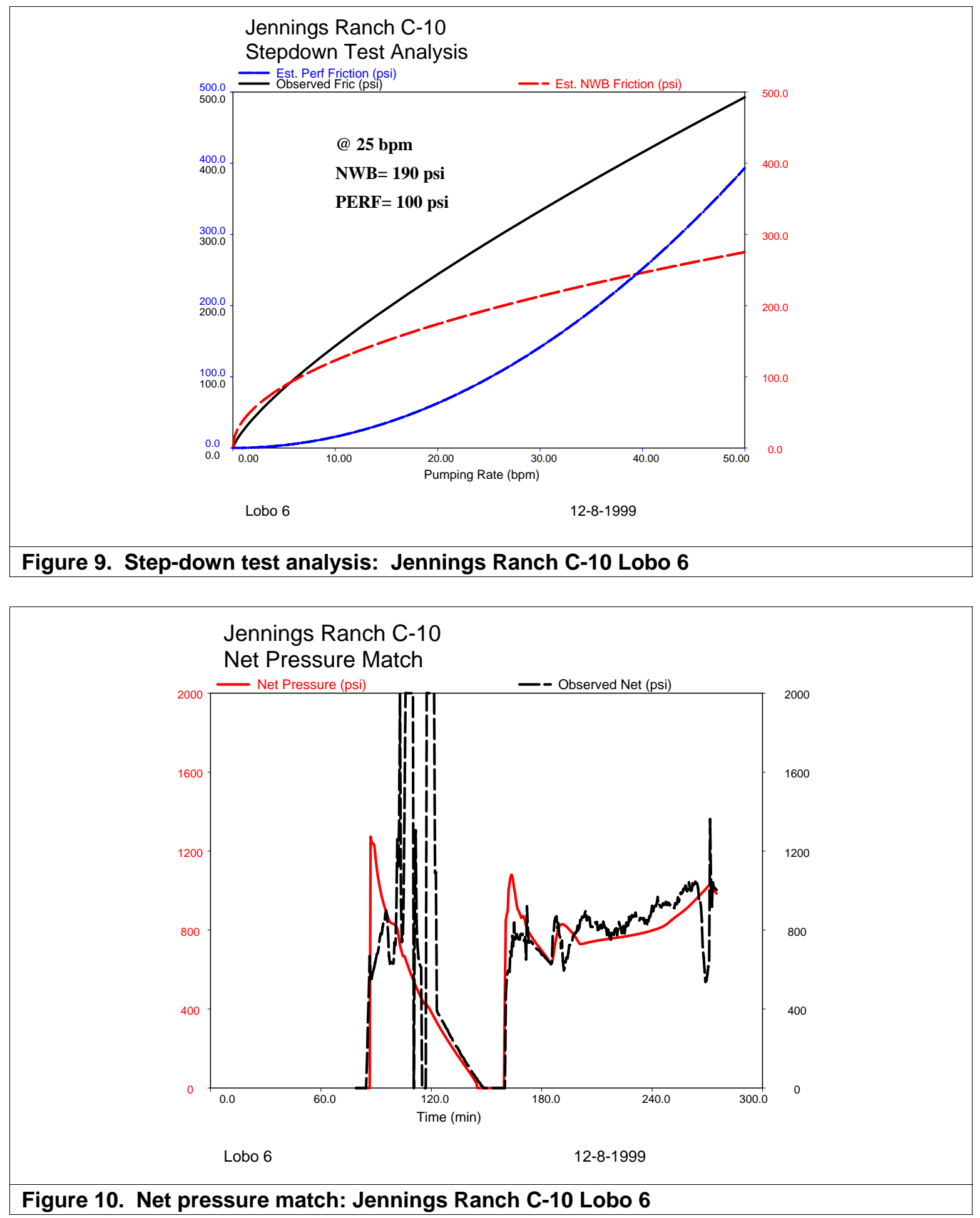


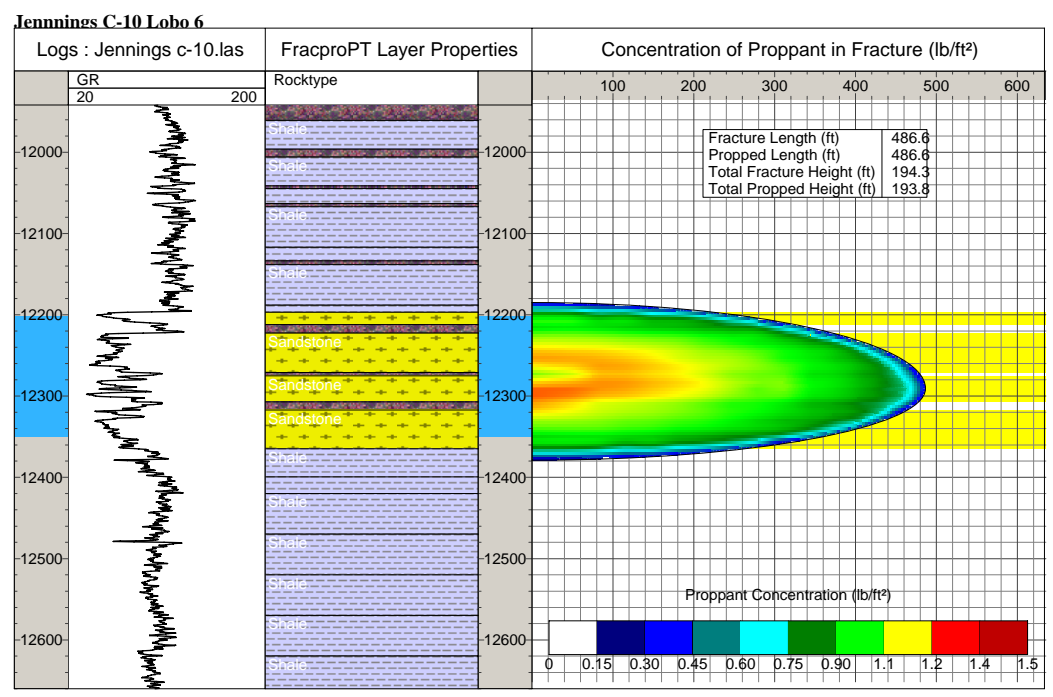

Figure 11. Model fracture geometry: Jennings Ranch C-10 Lobo 6

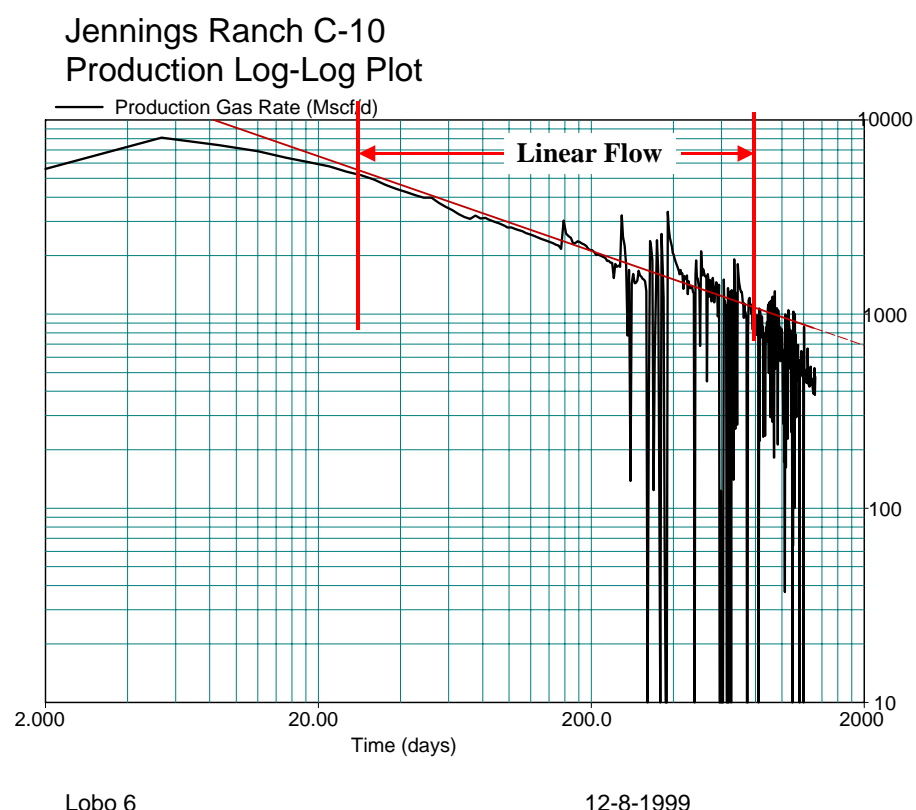

Figure 12. Log-log diagnostic plot of well production: Jennings Ranch C-10 Lobo 6 

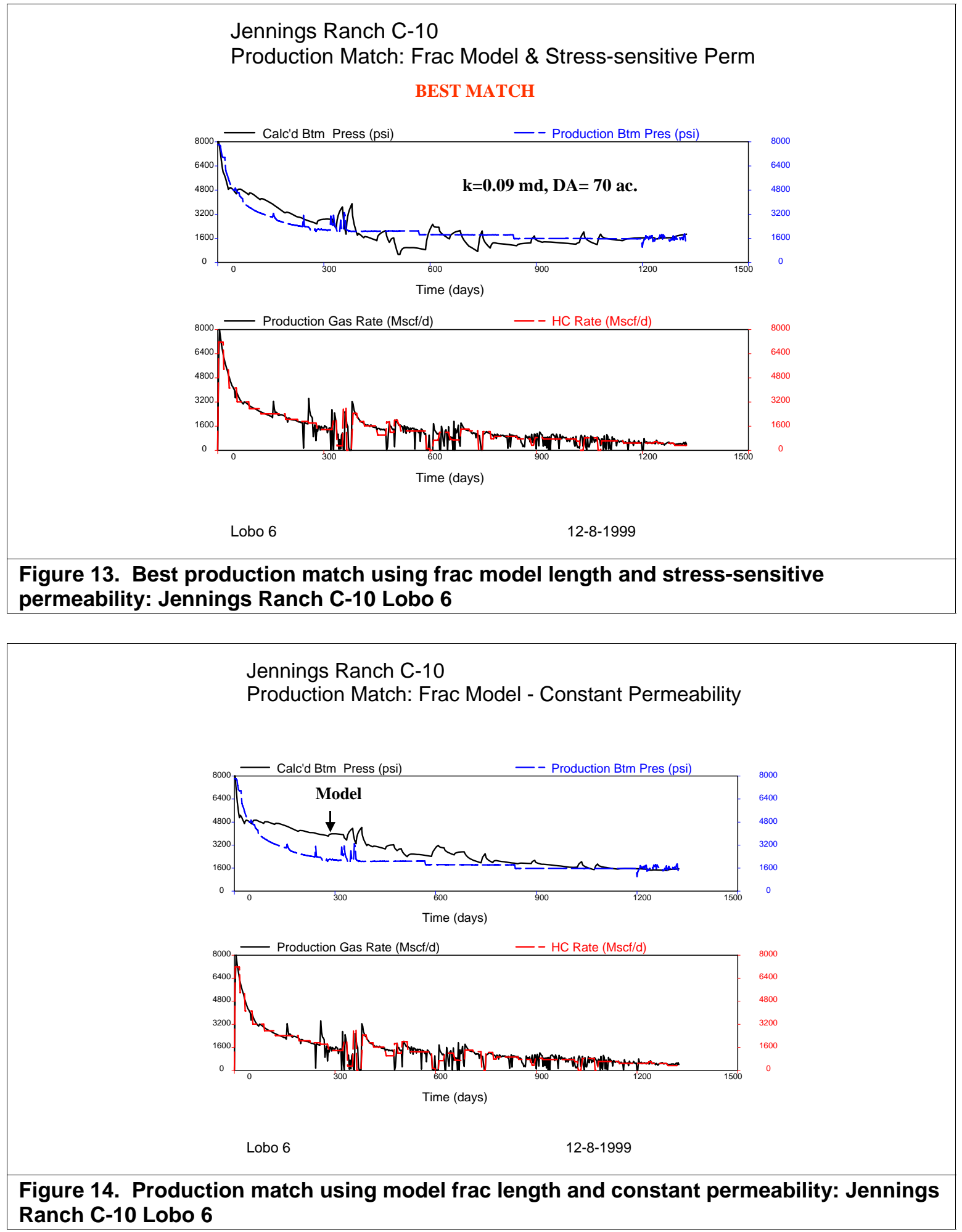


\subsubsection{Jennings Ranch C-12}

The net pressure match is shown in Figure 17. Fracture length is estimated to be about $600 \mathrm{ft}$ with some downward growth below the perforated interval. Stress-sensitive permeability was also used in this case to improve the quality of the flowing pressure match.


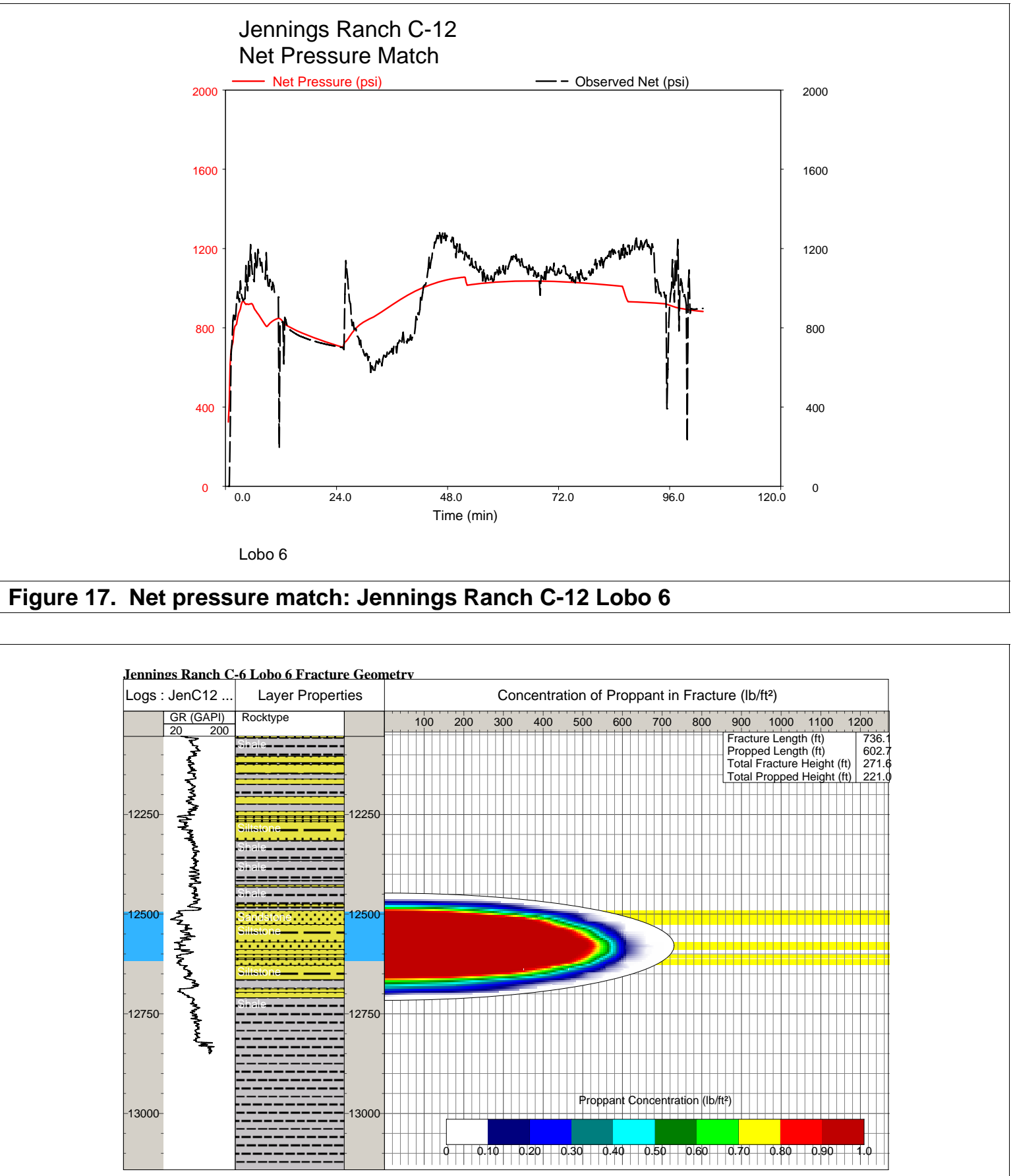

Figure 18. Model fracture geometry: Jennings Ranch C-12 Lobo 6 


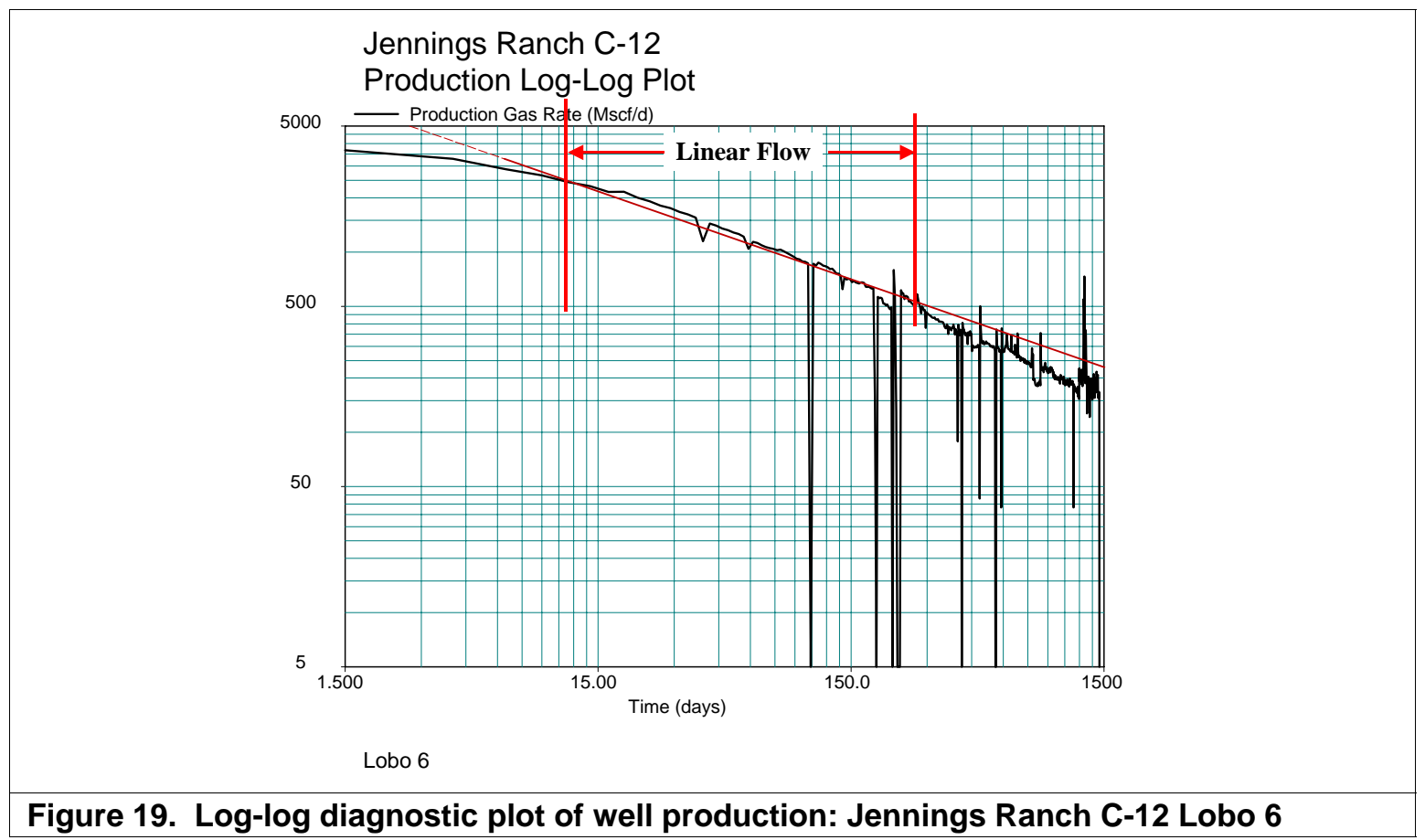

plot of well production: Jen

Jennings Ranch C-12

Production Match: Frac Model \& Stress-Sensitive Perm
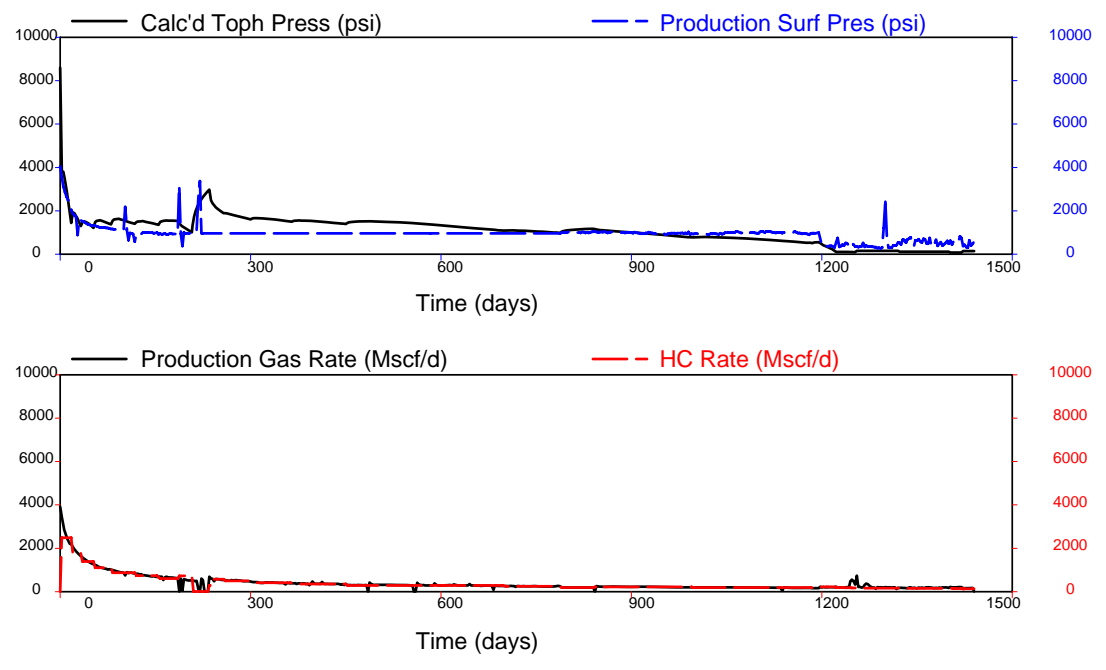

Lobo 6

Figure 20. Production match using model frac length and stress-sensitive permeability: Jennings Ranch C-12 Lobo 6 


\subsubsection{Jennings Ranch C-18}

The net pressure match is shown in Figure 23. Fracture length is estimated to be about $660 \mathrm{ft}$ with slight height growth around the perforated interval. In this case it was not necessary to model production with stress-sensitive permeability.

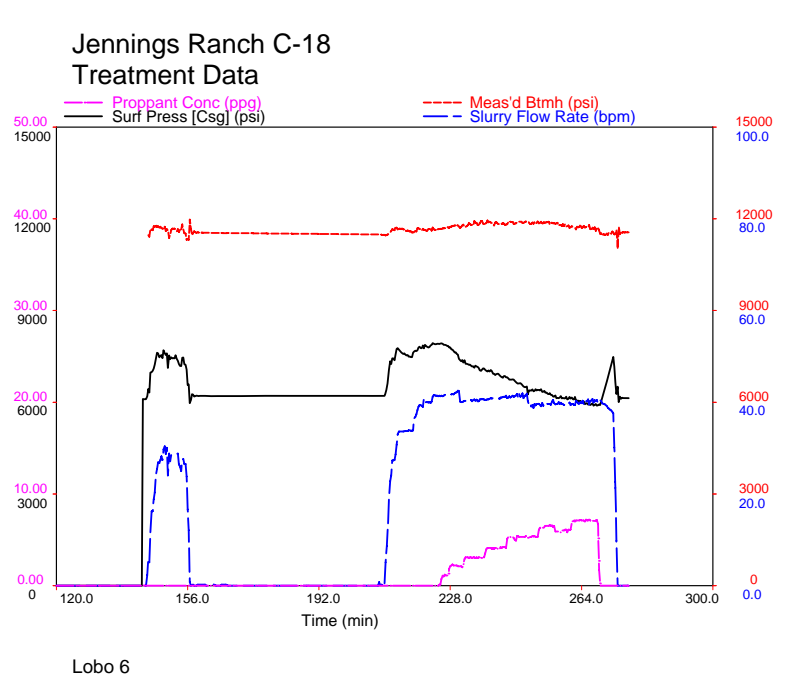

Figure 21. Treatment data: Jennings Ranch C-18 Lobo 6

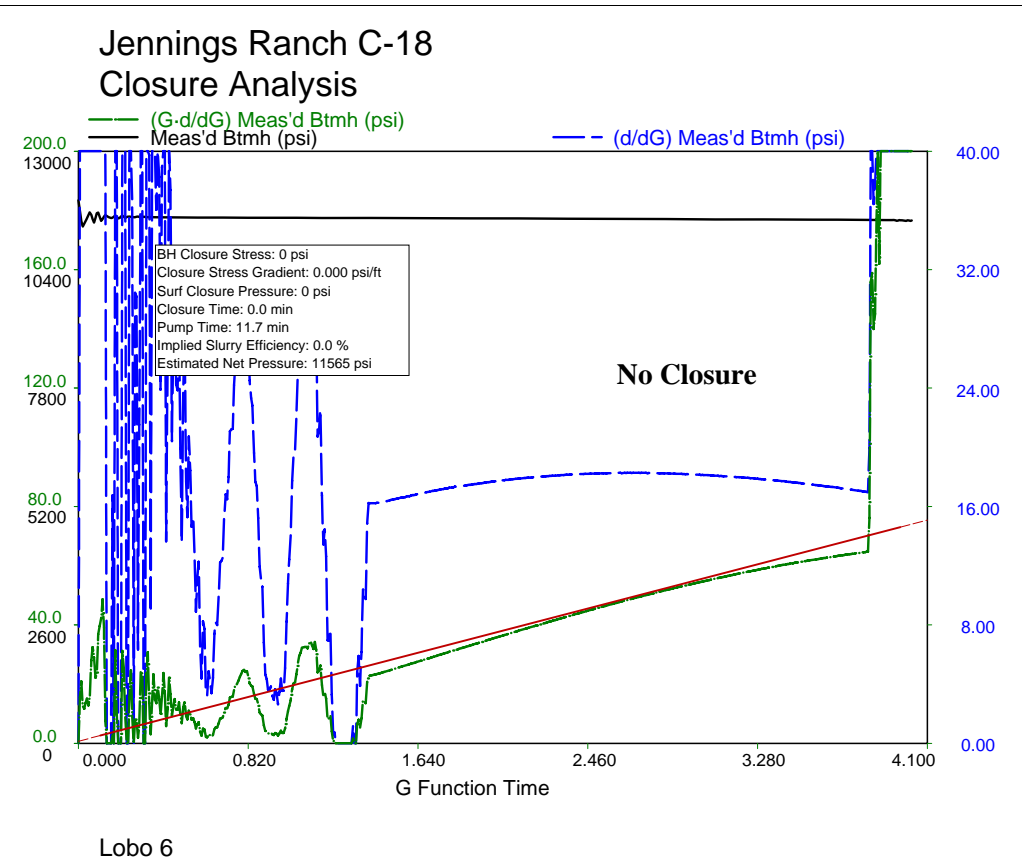

Figure 22. Closure analysis: Jennings Ranch C-12 Lobo 6 
Jennings Ranch C-18

Net Pressure Match

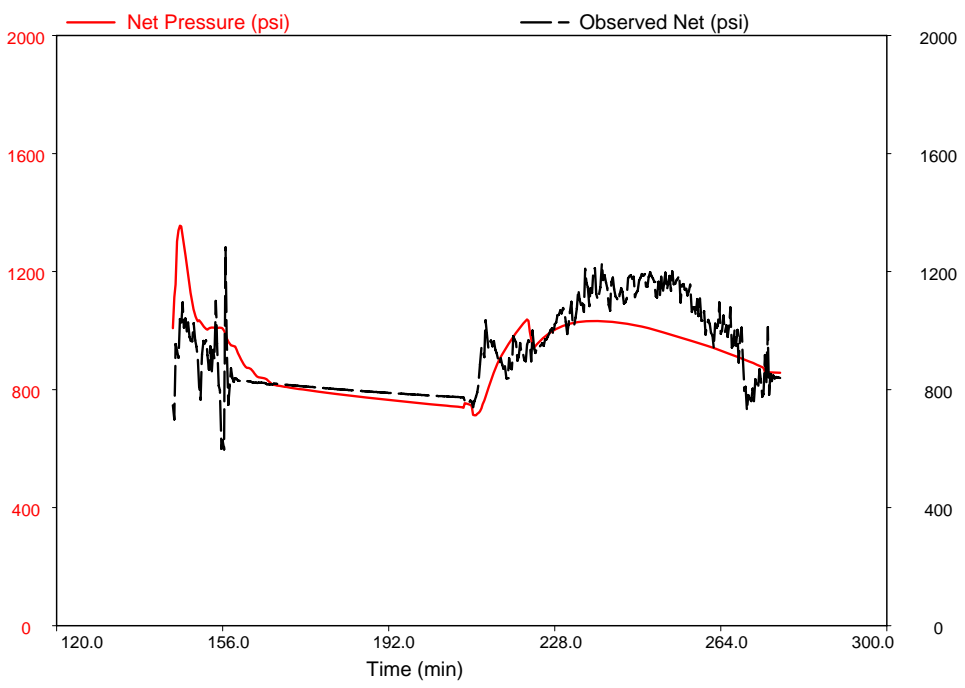

Lobo 6

Figure 23. Net pressure match: Jennings Ranch C-18 Lobo 6

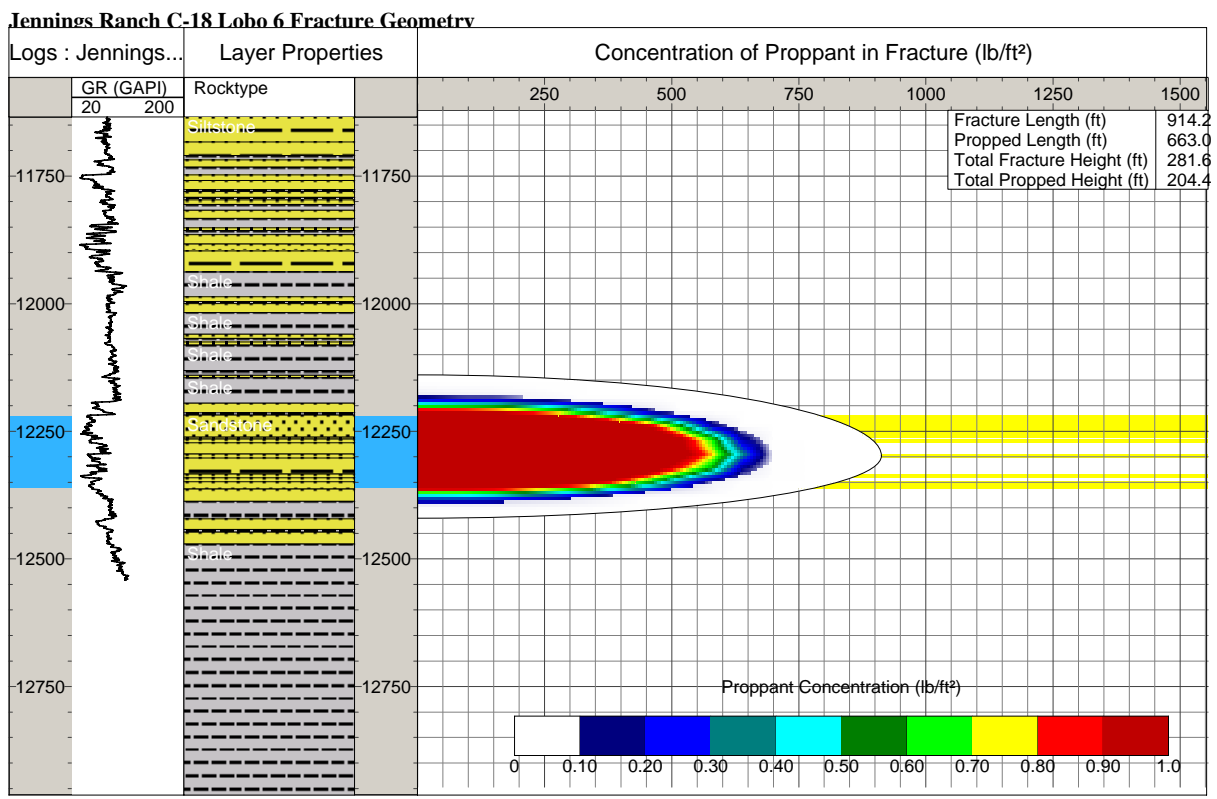

Figure 24. Model fracture geometry: Jennings Ranch C-18 Lobo 6 


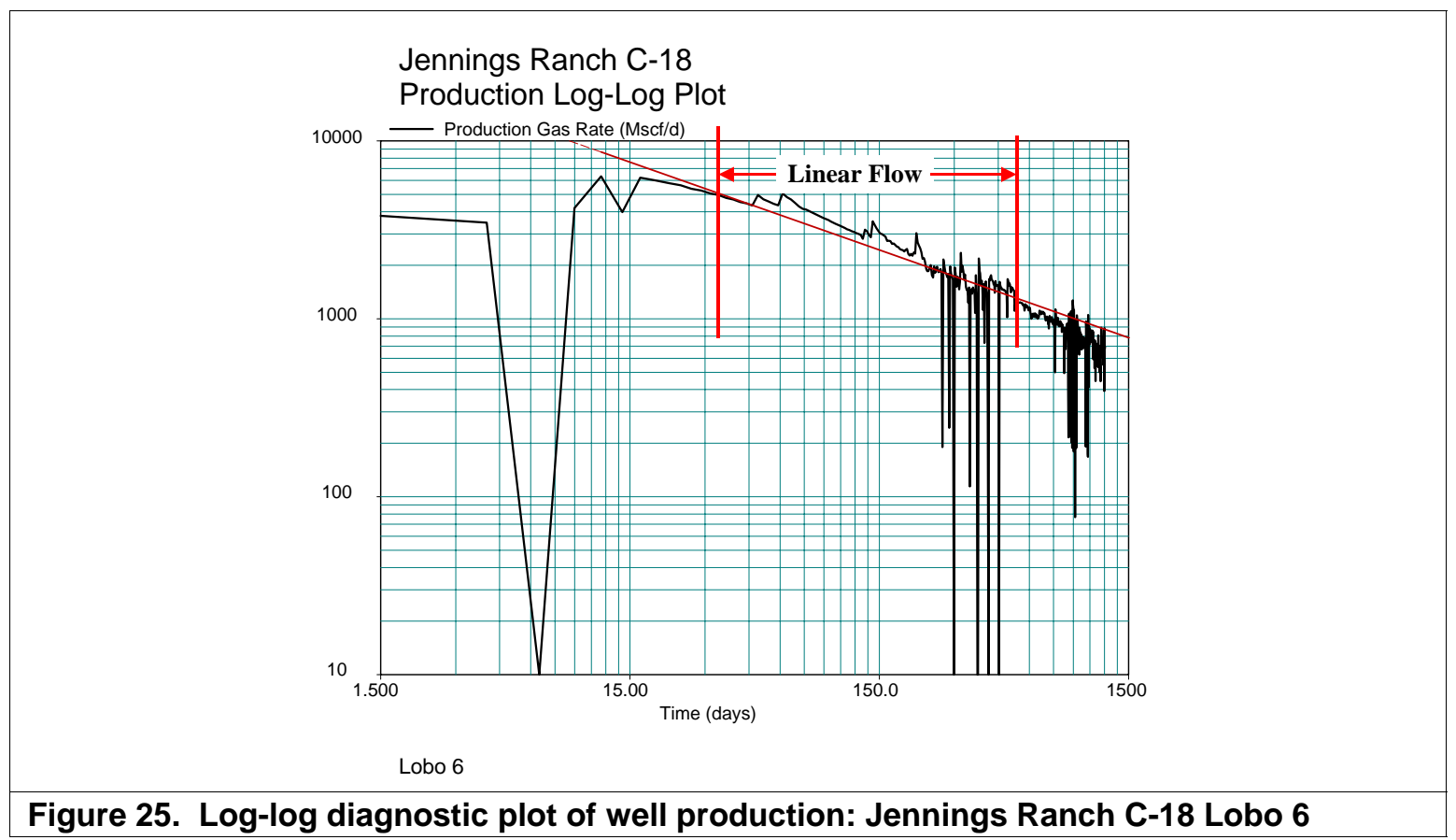

Figure 25. Log-log diagnostic plot of well production: Jennings Ranch C-18 Lobo 6

Jennings Ranch C-18

Production Match
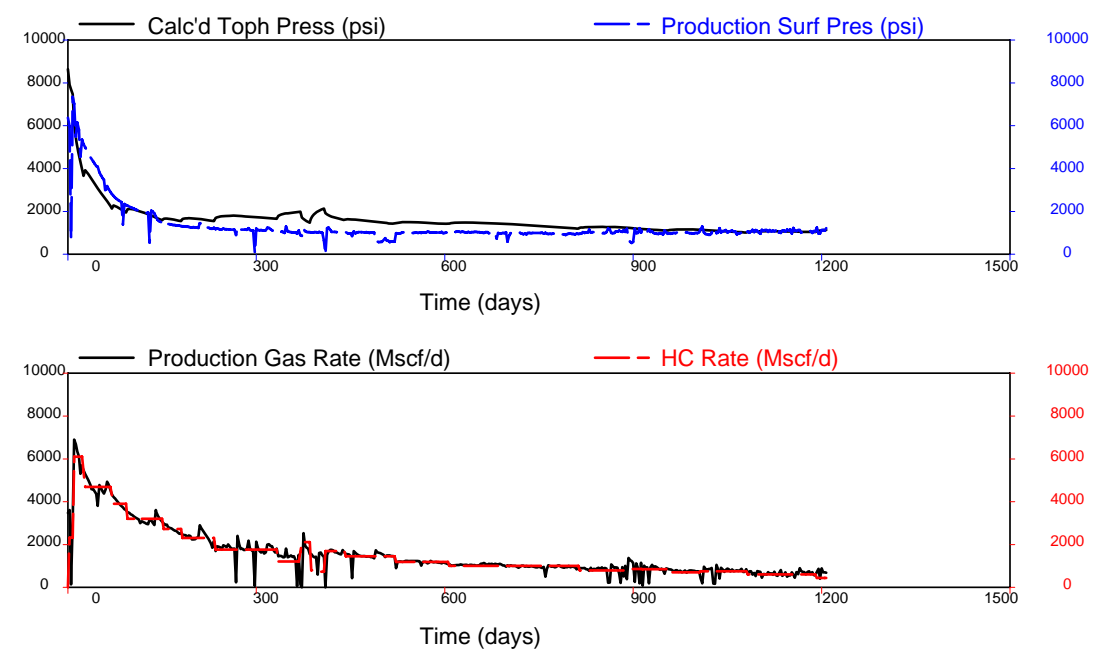

Lobo 6

Figure 26. Production match using model frac length and constant permeability: Jennings Ranch C-18 Lobo 6 


\subsubsection{Jennings Ranch C-19}

The net pressure match is shown in Figure 29. Fracture length is estimated to be about $400 \mathrm{ft}$ with slight height growth around the perforated interval. In this case it was not necessary to model production with stress-sensitive permeability.

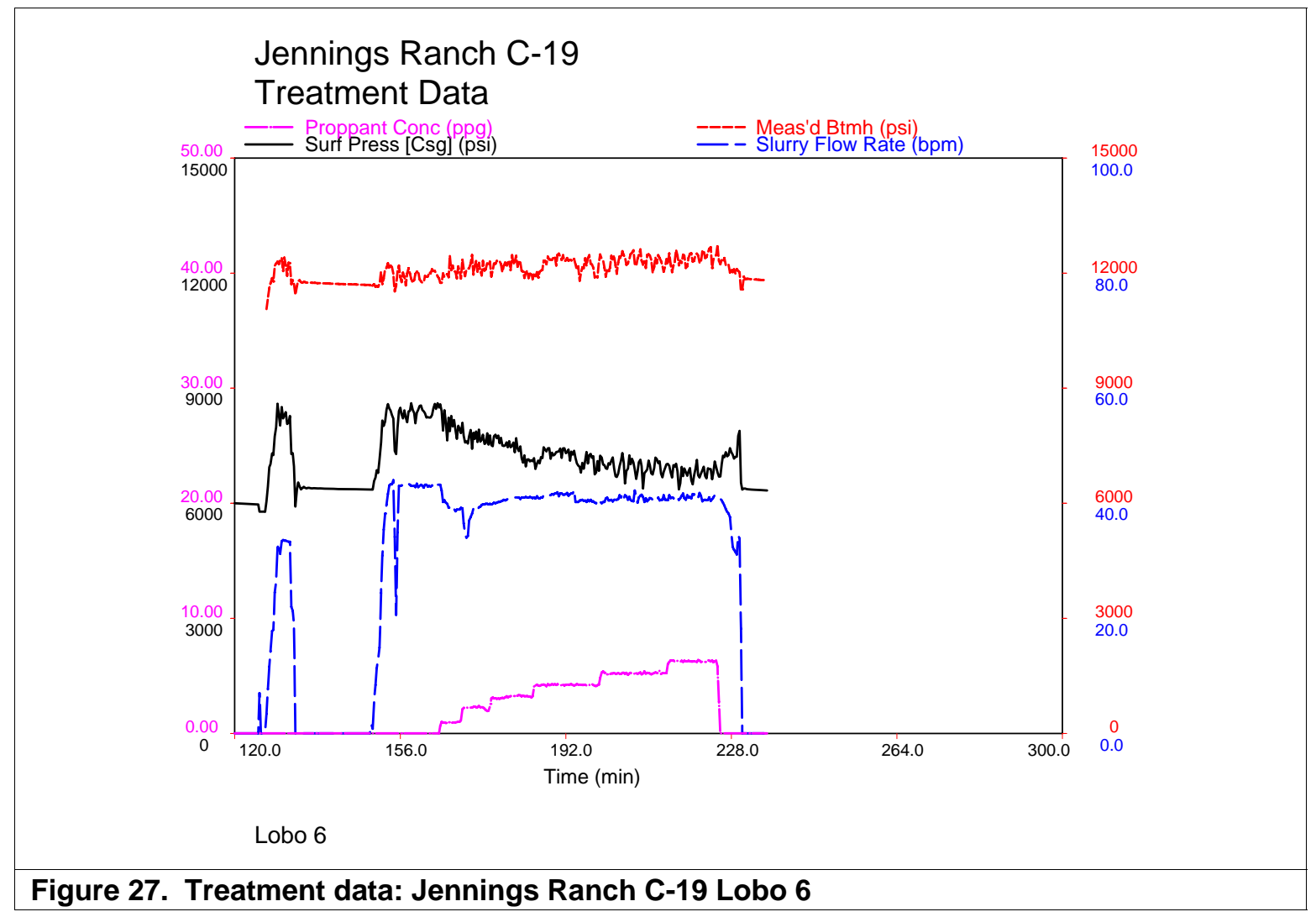




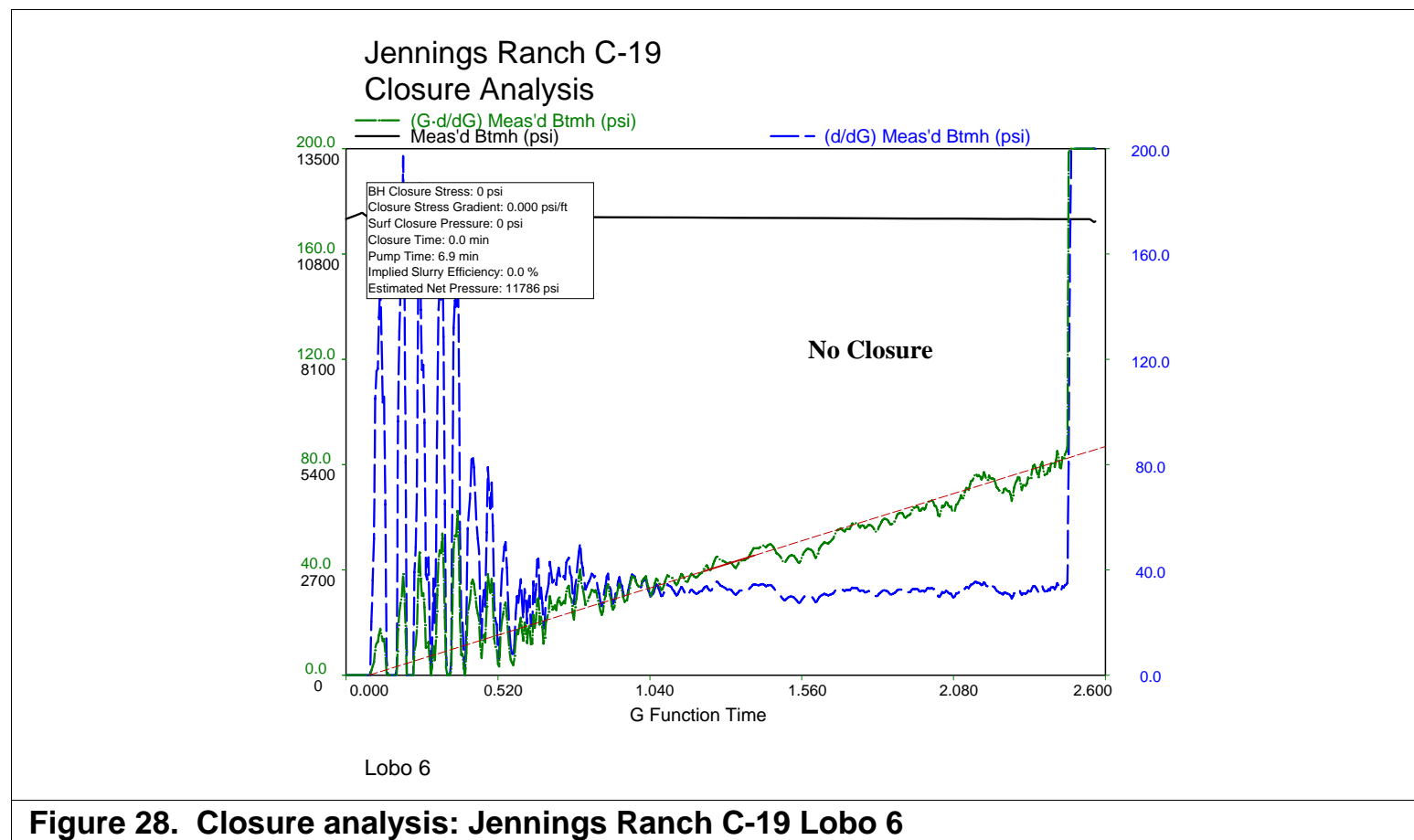

Figure 28. Closure analysis: Jennings Ranch C-19 Lobo 6

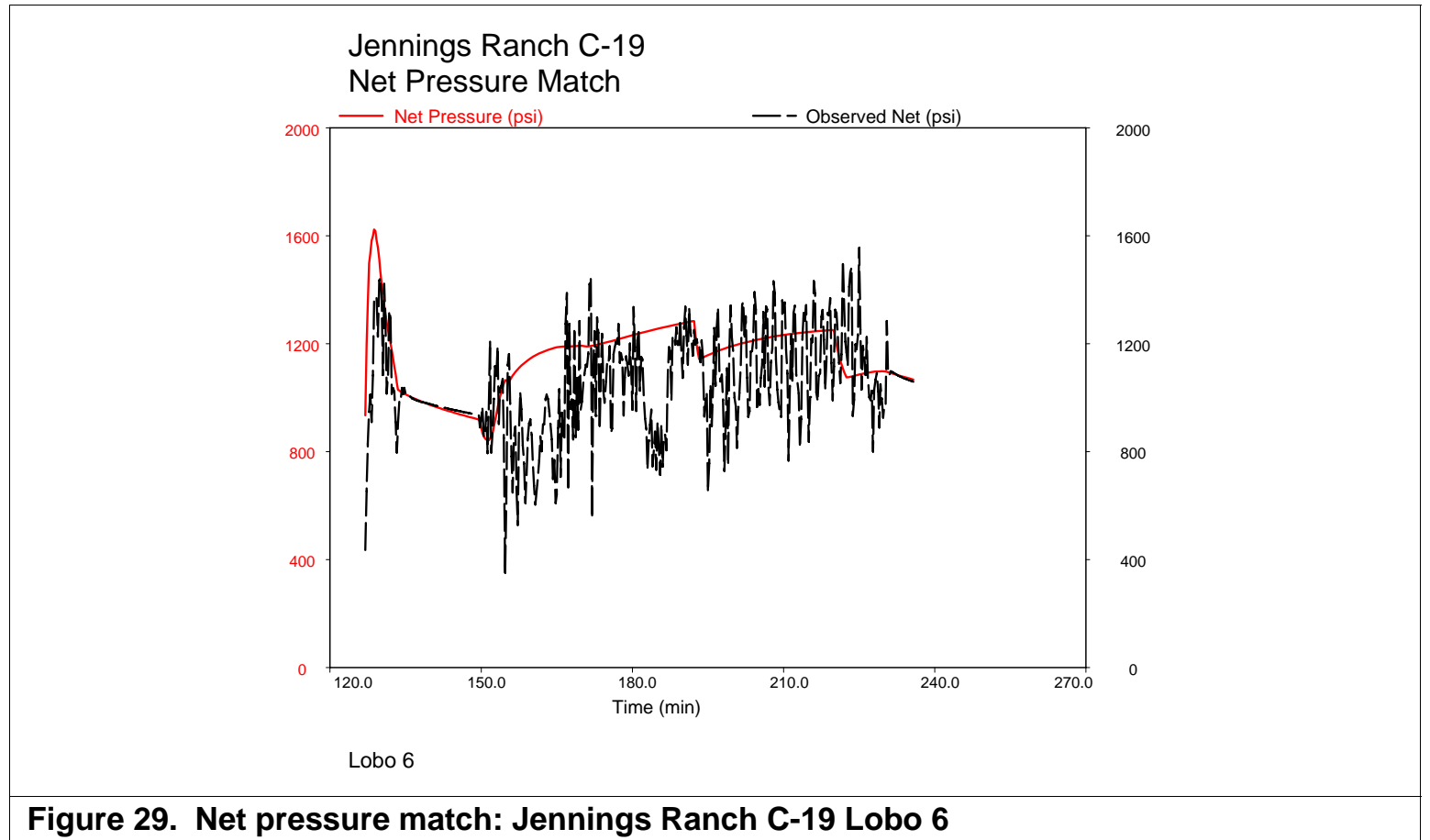




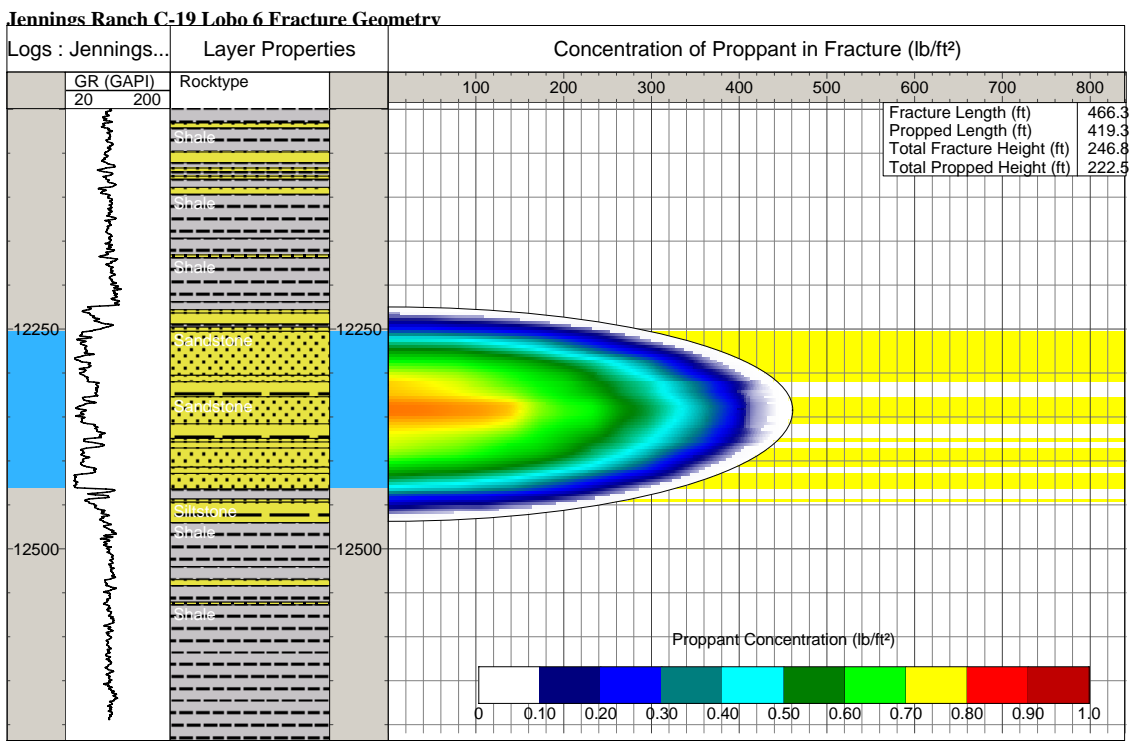

Figure 30. Model fracture geometry: Jennings Ranch C-19 Lobo 6

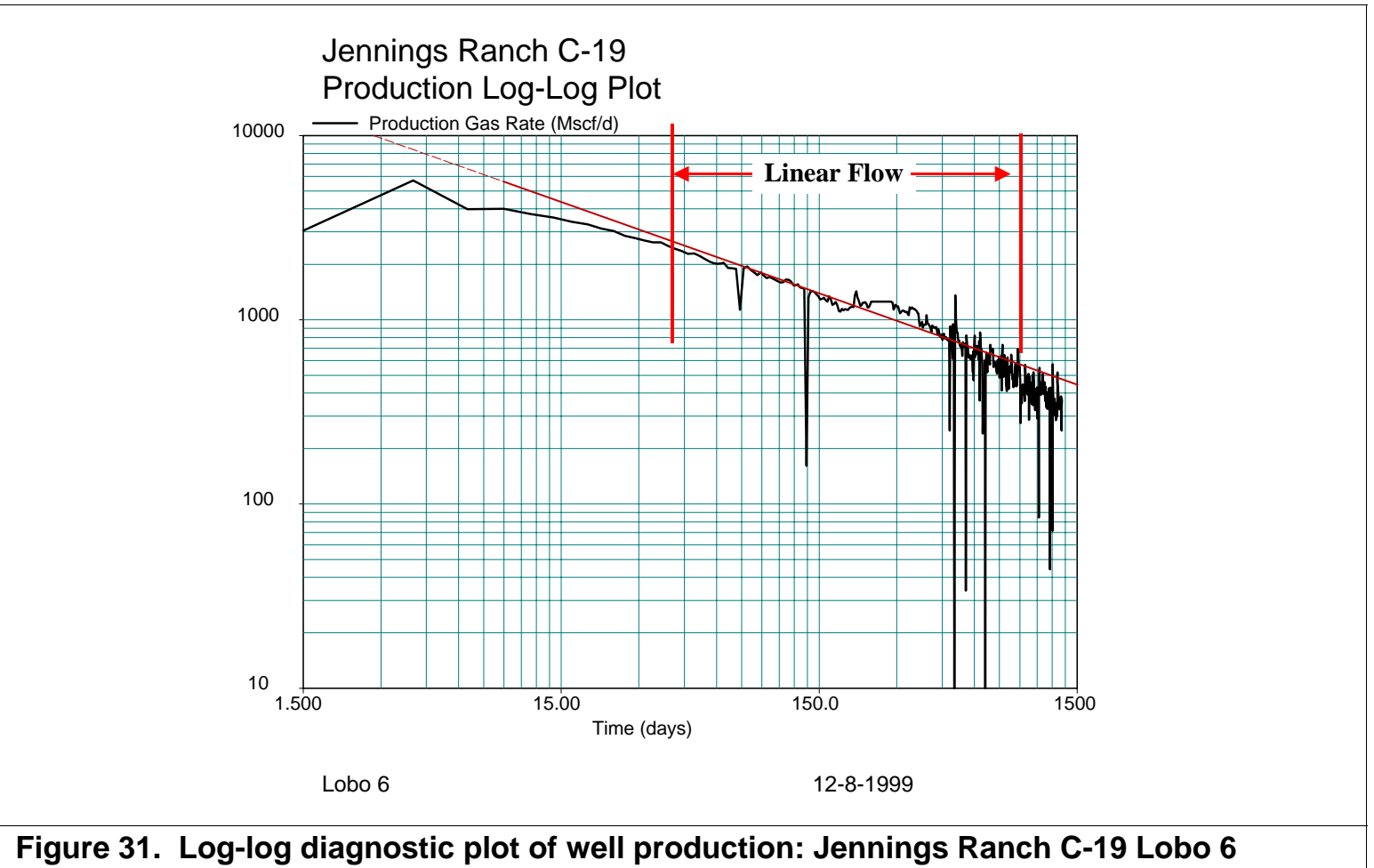




\section{Jennings Ranch C-19 \\ Production Match}
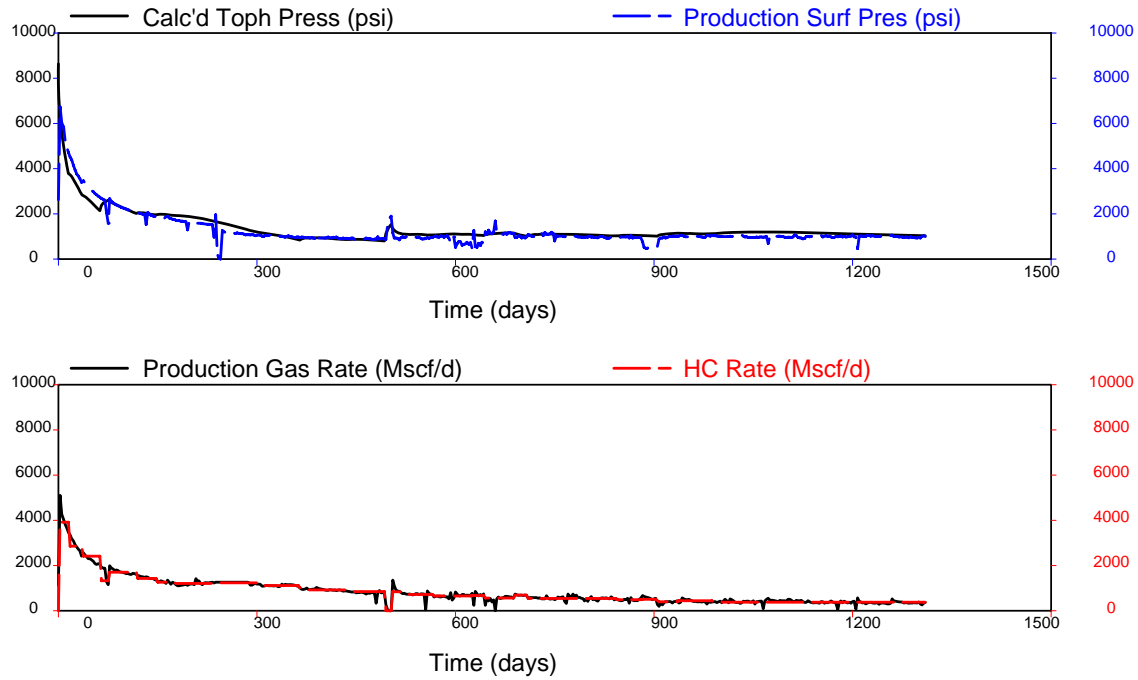

Lobo 6

Figure 32. Production match using model frac length and constant permeability: Jennings Ranch C-19 Lobo 6

\subsubsection{Jennings Ranch C-21}

The net pressure match is shown in Figure 35. Fracture length is estimated to be about $500 \mathrm{ft}$ with the fracture roughly covering the perforated interval. In this case it was not necessary to model production with stress-sensitive permeability. 

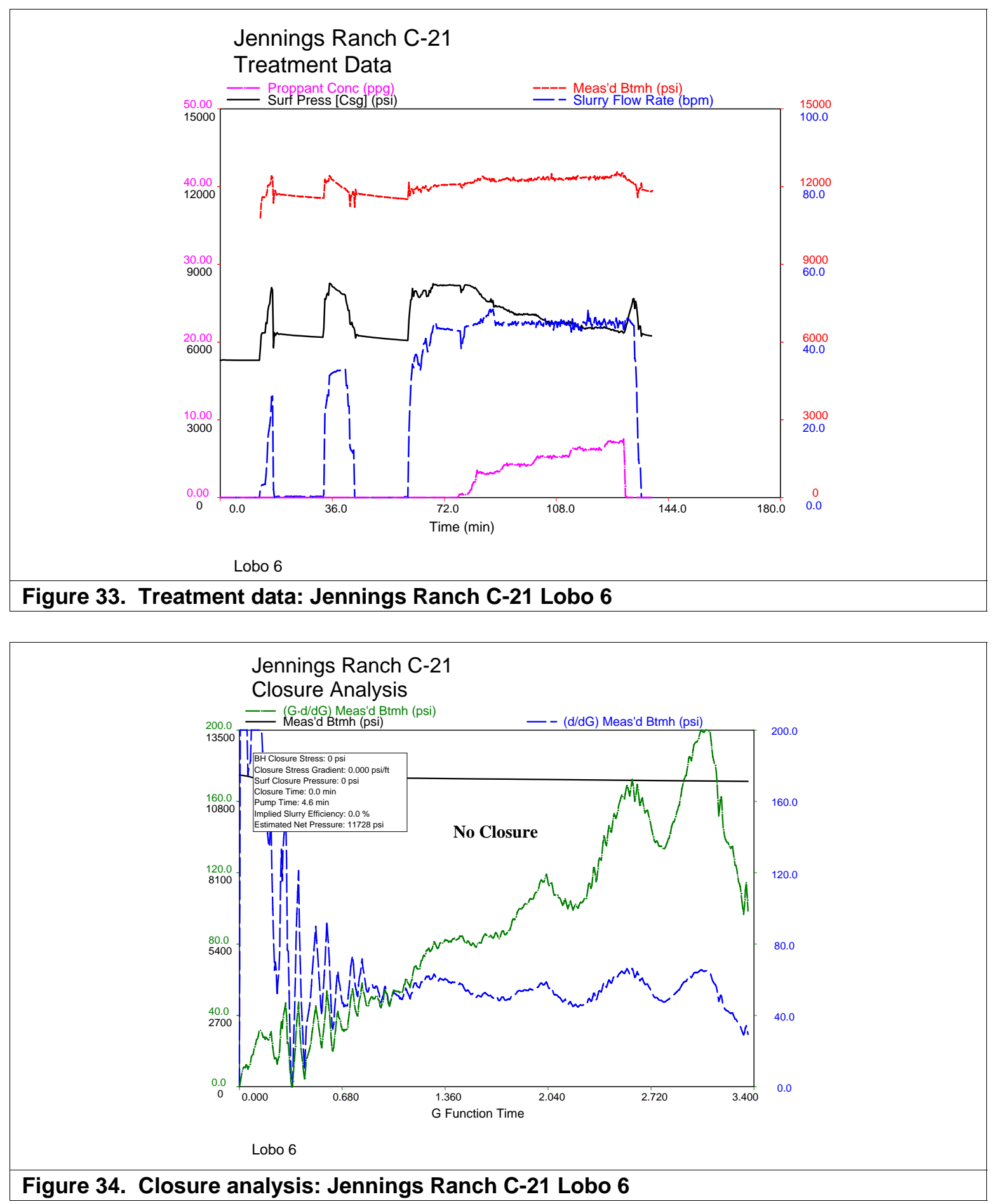
Jennings Ranch C-21

Net Pressure Match

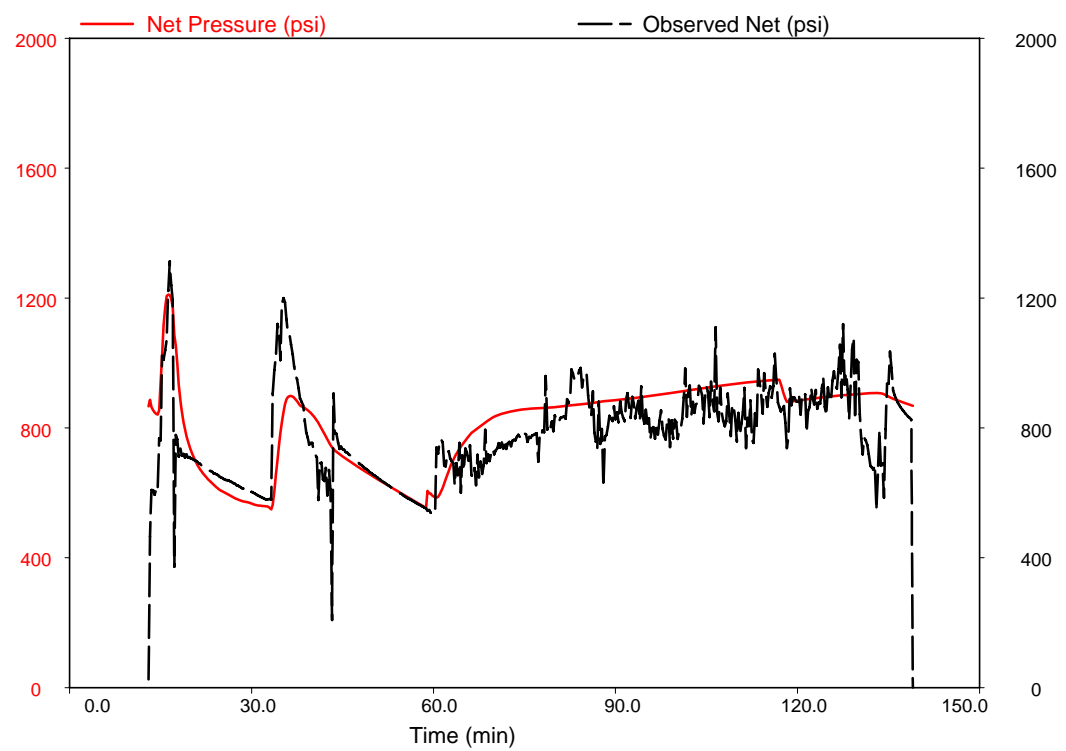

Lobo 6

Figure 35. Net pressure match: Jennings Ranch C-21 Lobo 6

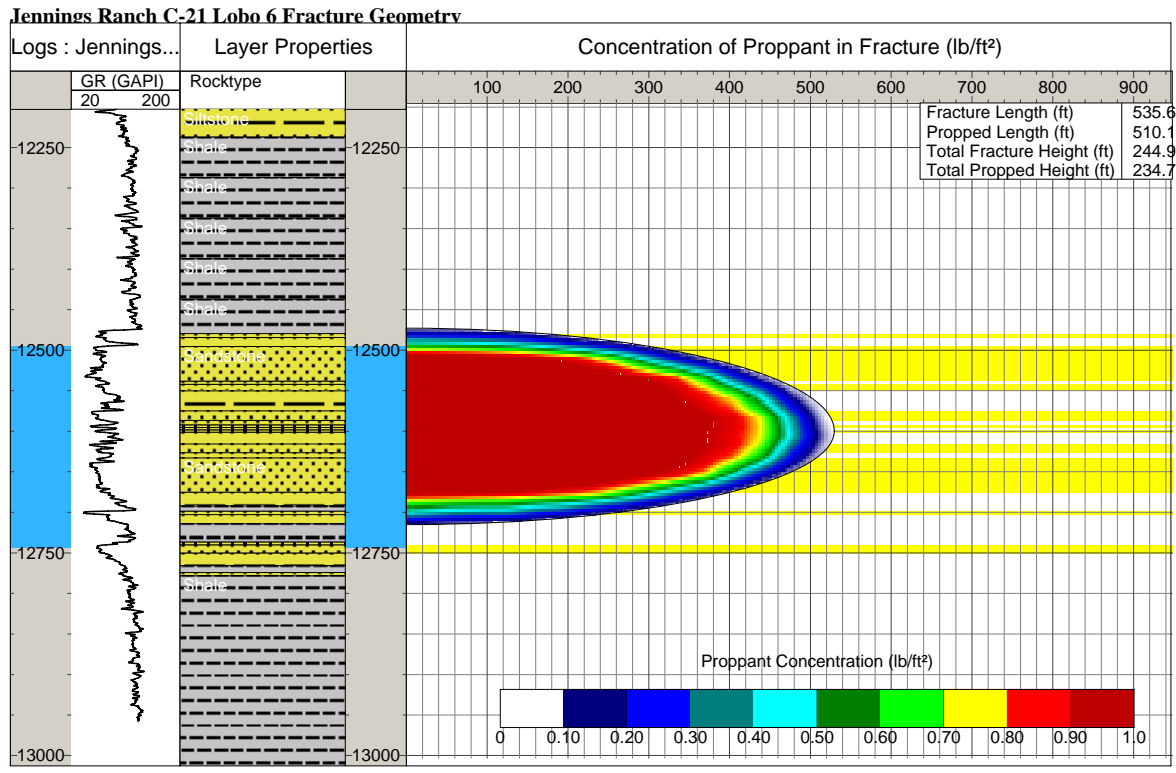

Figure 36. Model fracture geometry: Jennings Ranch C-21 Lobo 6 


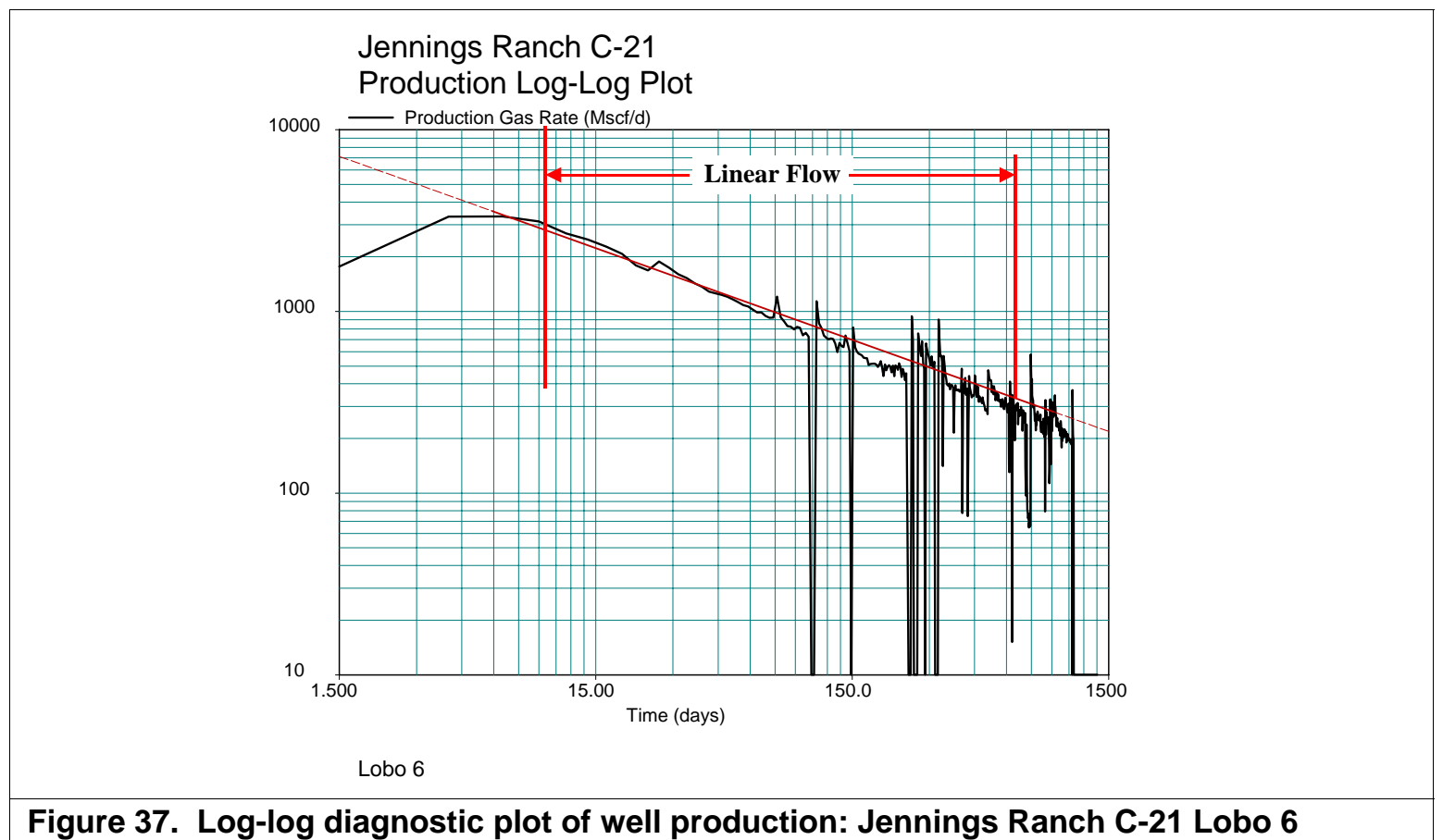

Figure 37. Log-log diagnostic plot of well production: Jennings Ranch C-21 Lobo 6

\section{Jennings Ranch C-21 \\ Production Match}
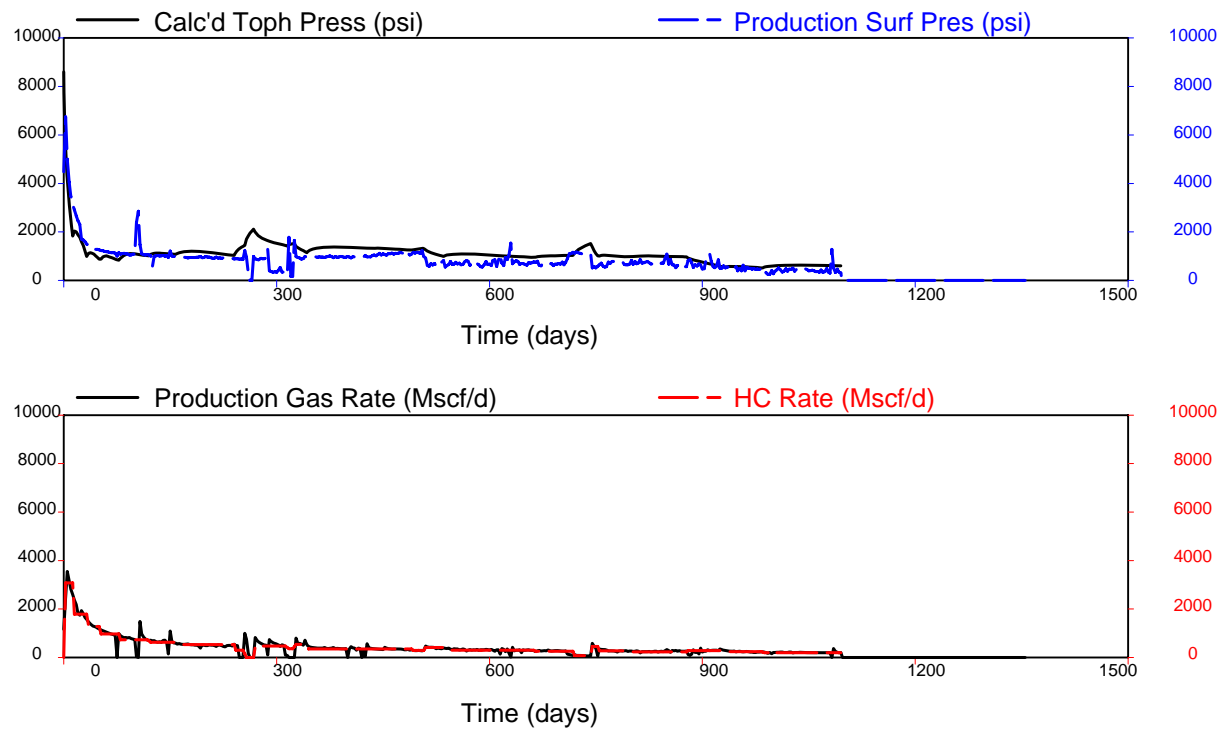

Lobo 6

Figure 38. Production match using model frac length and constant permeability: Jennings Ranch C-21 Lobo 6 


\subsubsection{Jennings Ranch C-24}

The net pressure match is shown in Figure 41. Fracture length is estimated to be about $400 \mathrm{ft}$ with the fracture height slightly more than the perforated interval. In this case it was not necessary to model production with stress-sensitive permeability.

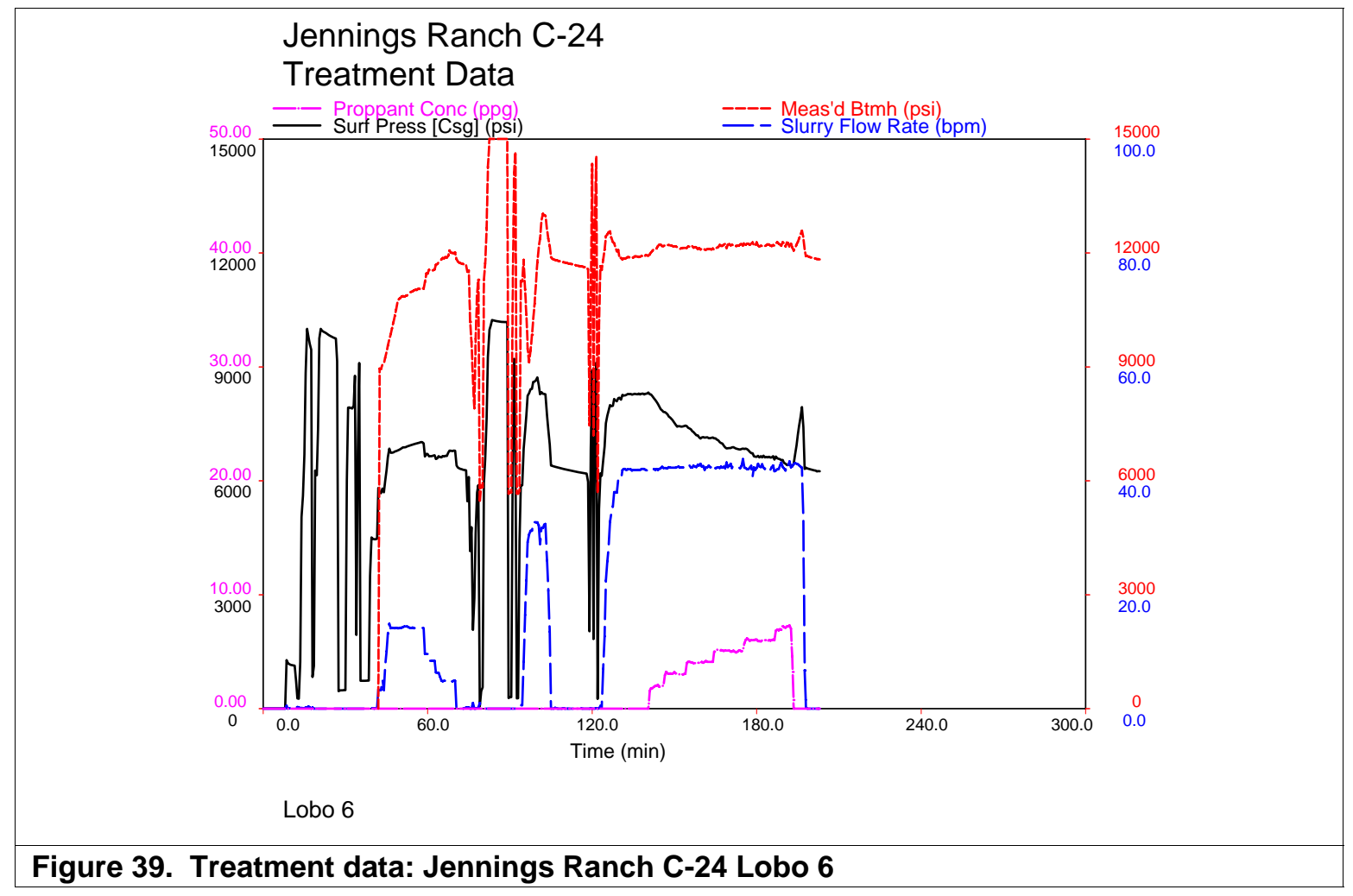



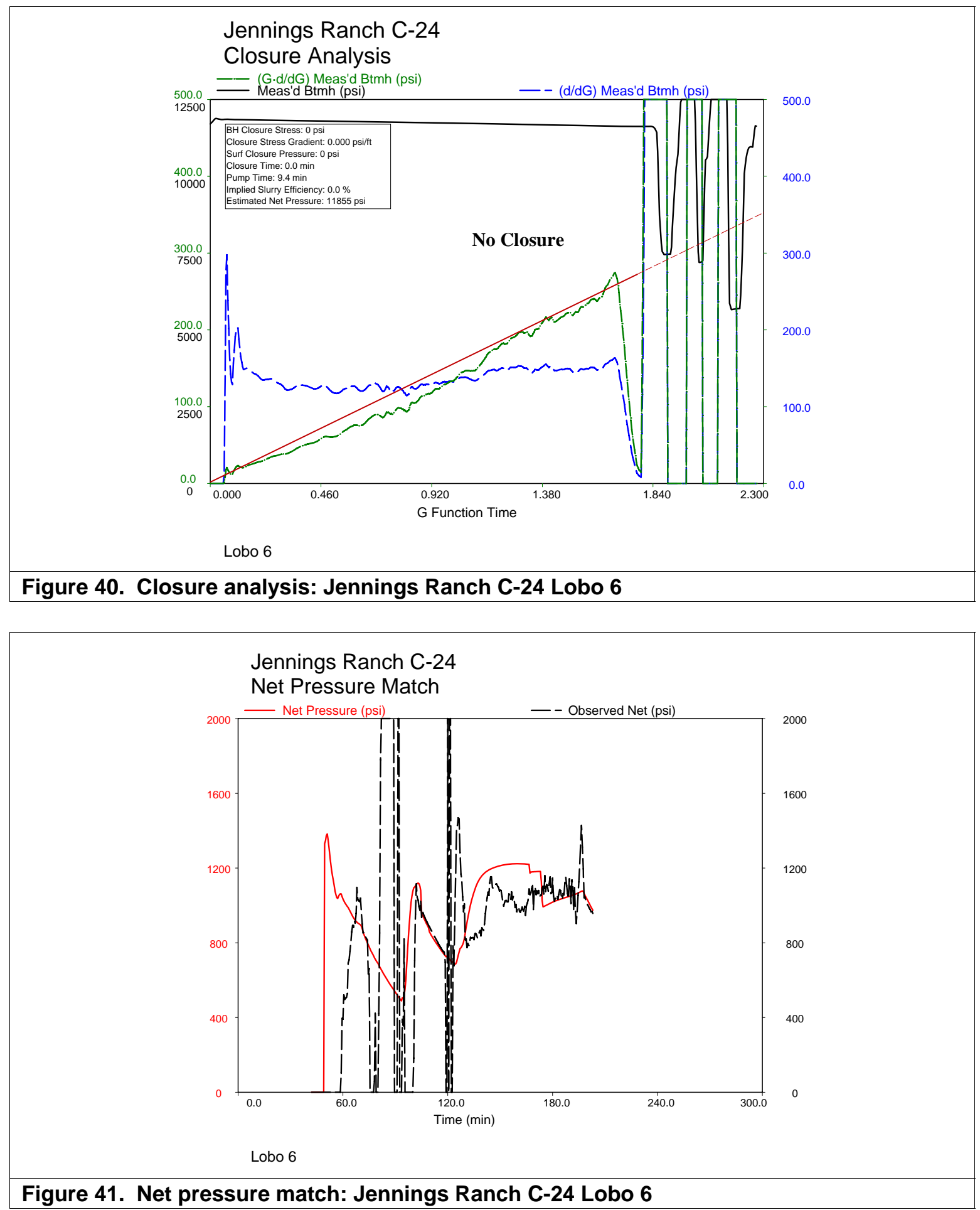


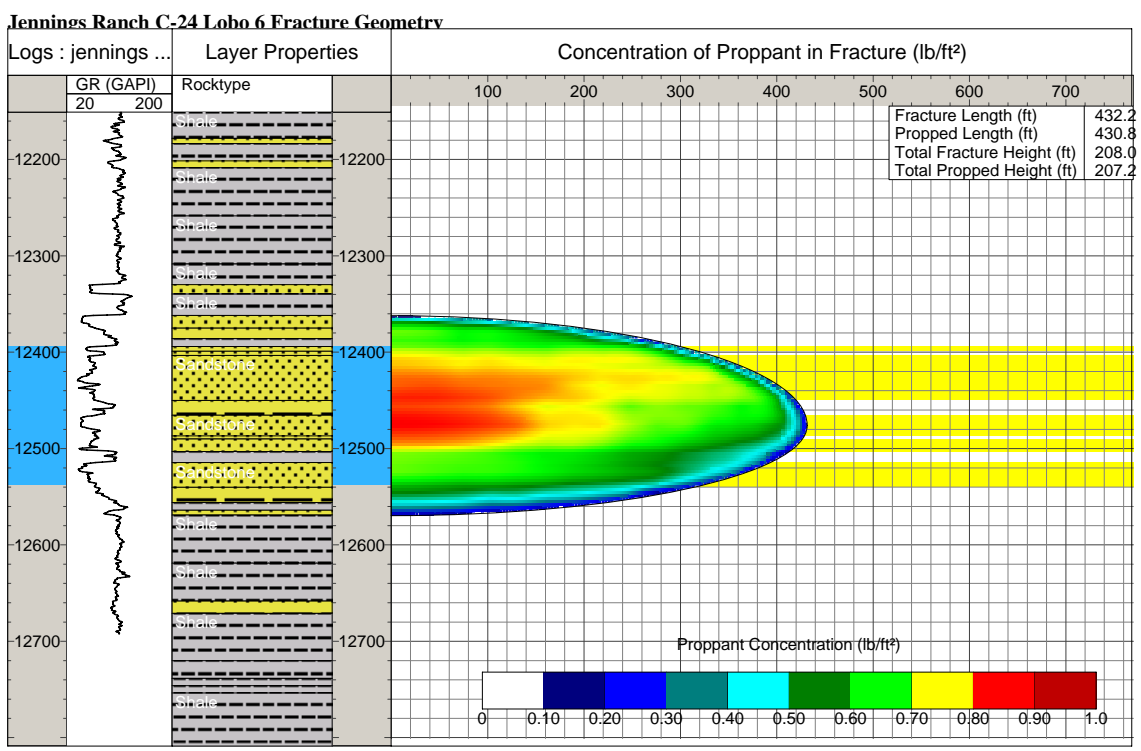

Figure 42. Model fracture geometry: Jennings Ranch C-24 Lobo 6

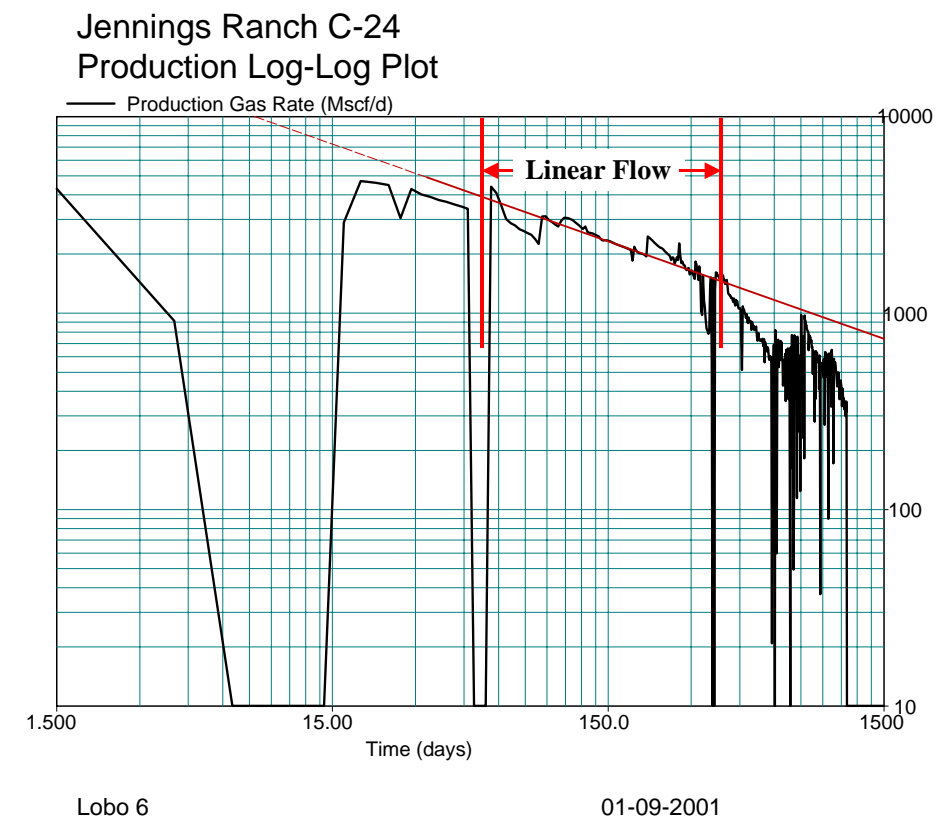

Figure 43. Log-log diagnostic plot of well production: Jennings Ranch C-24 Lobo 6 


\section{Jennings Ranch C-24 \\ Production Match}
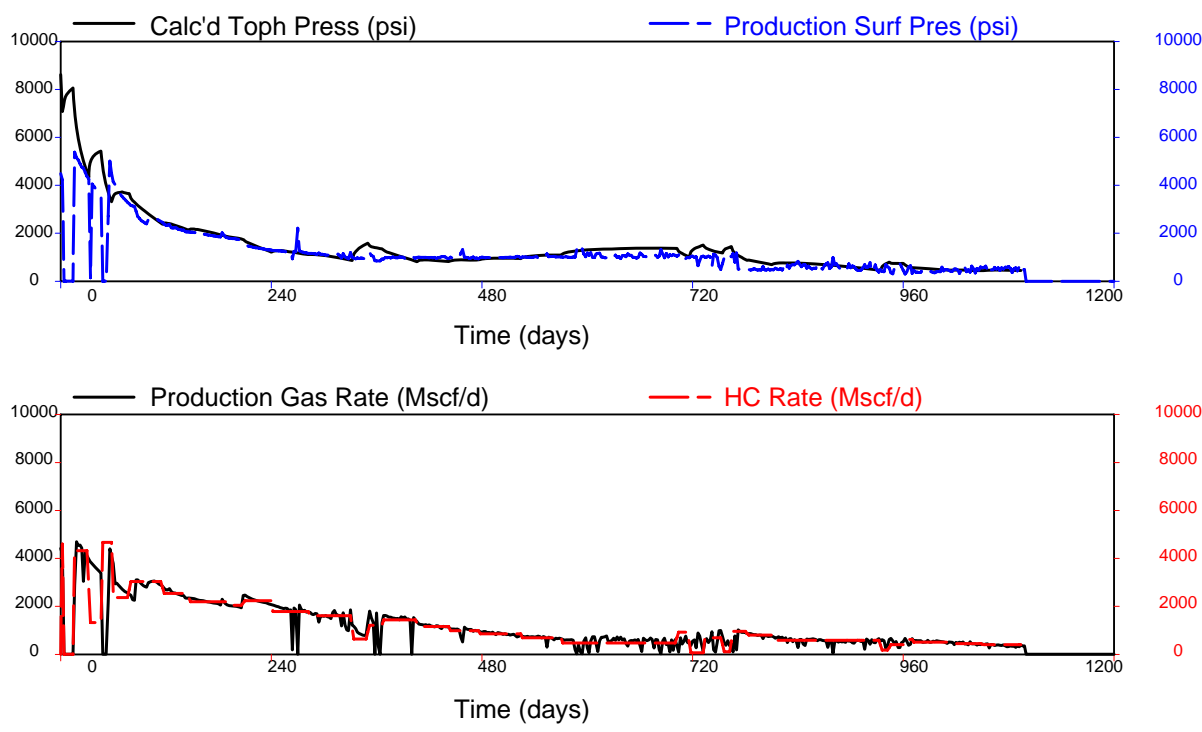

Lobo 6

01-09-2001

Figure 44. Production match using model frac length and constant permeability: Jennings Ranch C-24 Lobo 6

\subsection{Integration and Application of Results}

\subsubsection{Hydraulic Fracture Optimization}

Current well spacing is specified to be about three to four wells in 80 acre to 120 acre fault blocks. Using the well information in the Jennings Ranch C-12, a generic well was created to investigate what the optimum fracture length would be given three different well spacings (80 acres, 40 acres, and 20 acres). Net pay was assumed to be 60 feet, porosity 18\%, water saturation $50 \%$, permeability $0.02 \mathrm{md}$ and pore pressure 10,200 psi. Economic criteria were assumed to be $\$ 4.00$ flat gas price, $10 \%$ discount rate, and frac costs of about $\$ 1.00$ per pound of proppant with $1 / 3$ being fixed costs and 2/3 being variable costs depending on treatment size. These numbers are just rough assumptions but are mainly used to highlight the importance of fracture optimization for continued infill drilling.

The results show that optimum fracture size depends heavily on well spacing. For 80 acre spacing optimum frac size is $420 \mathrm{klb}$ (Figure 45), for 40 acre spacing the optimum size decreases to about $240 \mathrm{klb}$ (which is close to current designs) (Figure 46), and for continued infill drilling to 20 acre spacing, optimum size would decrease to about 130 klb (Figure 47). 


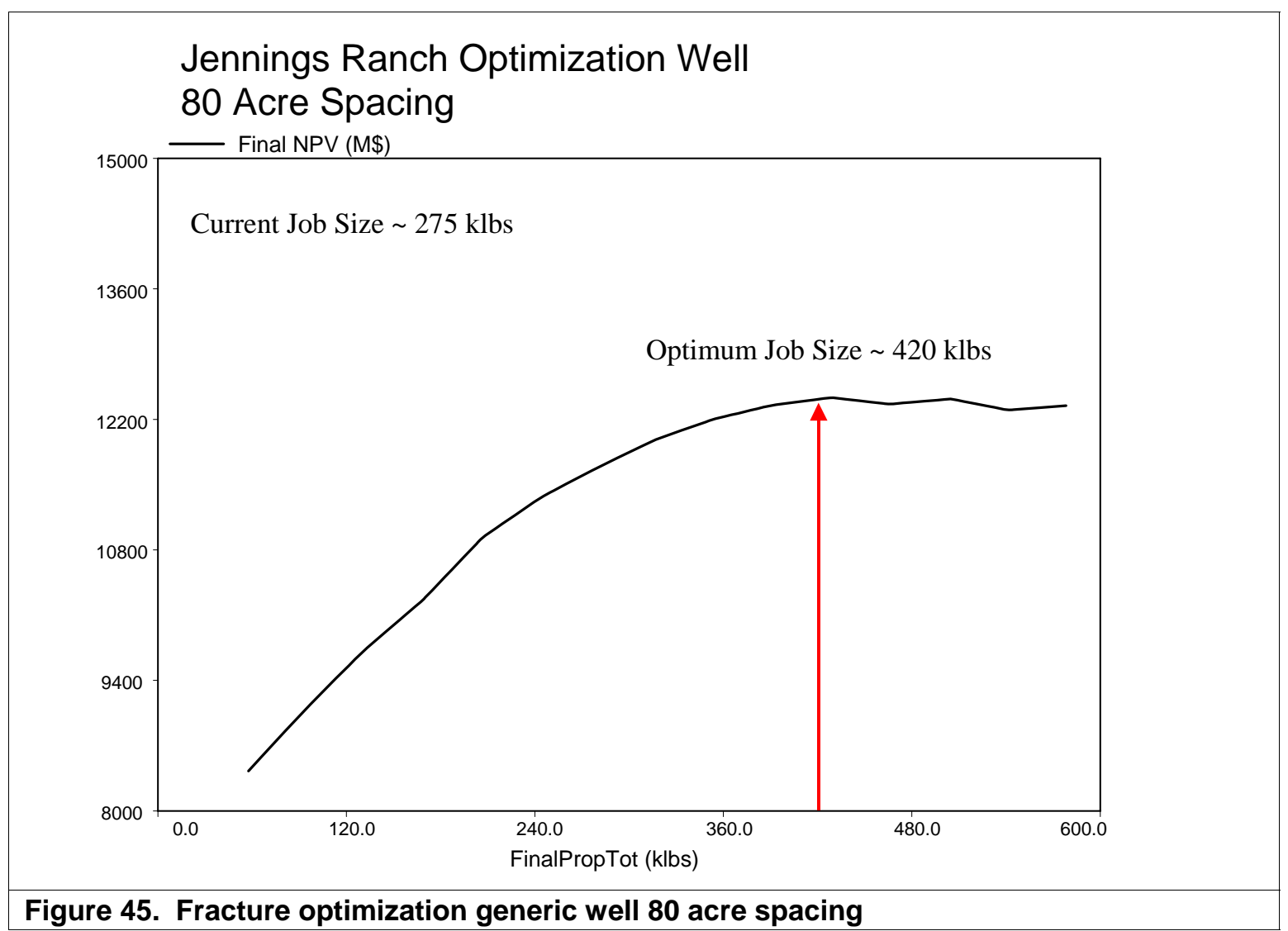




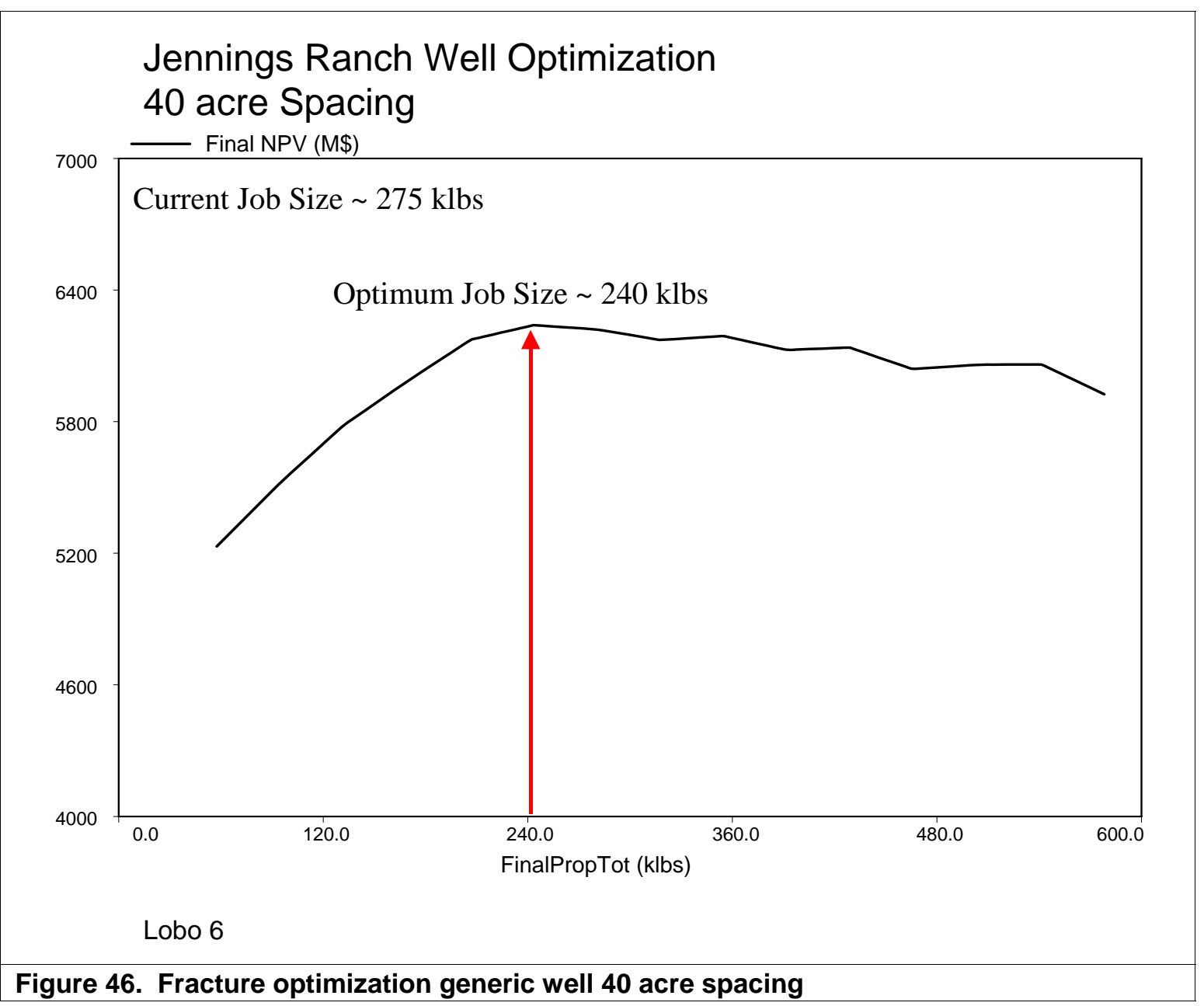




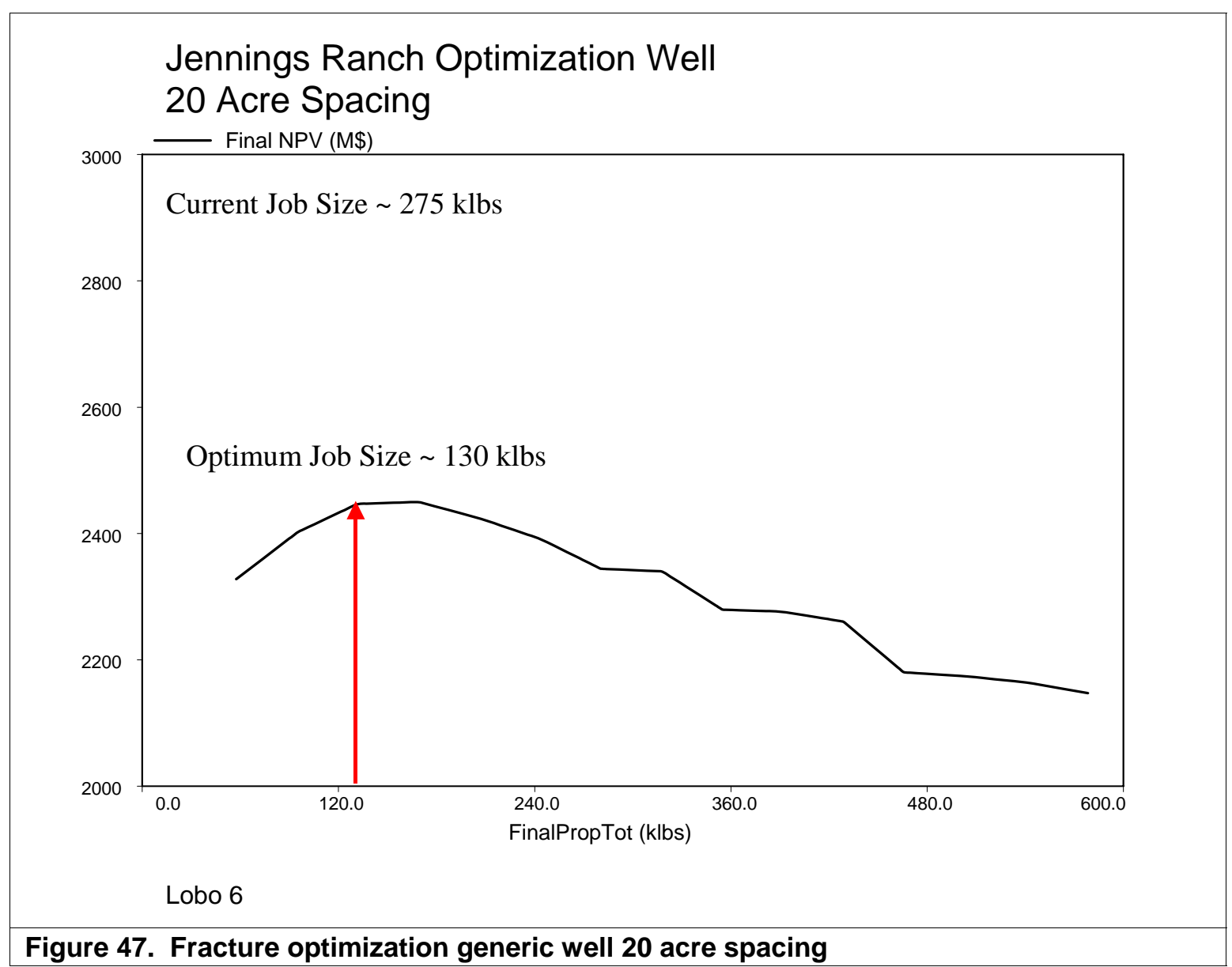

